\title{
GLI2 induces genomic instability in human keratinocytes by inhibiting apoptosis
}

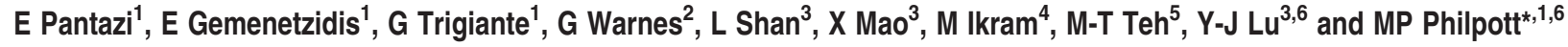

Abnormal Sonic Hedgehog signalling leads to increased transcriptional activation of its downstream effector, glioma 2 (GLI2), which is implicated in the pathogenesis of a variety of human cancers. However, the mechanisms underlying the tumorigenic role of GLI2 remain elusive. We demonstrate that overexpression of GLI2- $\beta$ isoform, which lacks the N-terminal repressor domain $(G L I 2 \Delta N)$ in human keratinocytes is sufficient to induce numerical and structural chromosomal aberrations, including tetraploidy/aneuploidy and chromosomal translocations. This is coupled with suppression of cell cycle regulators p21 WAF1/CIP1 and 14-3-3 $\sigma$, and strong induction of anti-apoptotic signalling, resulting in a reduction in the ability to eliminate genomically abnormal cells. Overexpression of GLI2 $\Delta \mathrm{N}$ also rendered human keratinocytes resistant to UVB-mediated apoptosis, whereas inhibition of B-cell lymphoma 2 (BCL-2) restored endogenous (genomic instability (GIN)) and exogenous (UVB) DNA damageinduced apoptosis. Thus, we propose that ectopic expression of GLI2 profoundly affects the genomic integrity of human epithelial cells and contributes to the survival of progenies with genomic alterations by deregulating cell cycle proteins and disabling the apoptotic mechanisms responsible for their elimination. This study reveals a novel role for GLI2 in promoting GIN, a hallmark of human tumors, and identifies potential mechanisms that may provide new opportunities for the design of novel forms of cancer therapeutic strategies.

Cell Death and Disease (2014) 5, e1028; doi:10.1038/cddis.2013.535; published online 30 January 2014

Subject Category: Cancer

Multiple genetic alterations are required for cancer development, and understanding the mechanisms that promote and enhance DNA damage is important. One of the hallmarks of cancer is genomic instability (GIN) and this is reflected in the heterogeneity seen within individual tumors and the extensive genomic alterations in cancer cells, responsible for both cancer development and treatment failure. ${ }^{1}$ GIN refers to a set of events capable of causing unscheduled alterations either of a temporary or permanent nature within the genome. ${ }^{2}$ GIN can be divided into two major groups: (1) microsatellite instability, occurring at the nucleotide level, due to faulty DNA repair pathways and (2) chromosomal instability (CIN), defined as an accelerated rate of chromosomal alterations due to increased chromosome damage, defects in end-joining repair mechanisms and errors in chromosome segregation. $^{2-4}$ Chromosome alterations, which commonly occur in human cancers, can be classified as structural alterations, including inversions, deletions, amplifications, duplications and translocations, and numerical changes denoting gains or losses of whole chromosomes, leading to aneuploidy. 2,4,5 Genomic abnormalities tend to induce apoptosis as a default pathway that aborts cells with damaged DNA. ${ }^{4,6-8}$ In addition to the increased rate in generating genomic alterations, inactivation of checkpoint and genomic surveillance genes is critical during the development of GIN by allowing the accumulation of gene mutations, chromosome damage and ploidy abnormalities. ${ }^{2-4,7,8}$

Basal cell carcinoma (BCC) of the skin is the most common malignancy in humans. Several studies have provided evidence of GIN in BCCs, highlighting their multiclonal nature and the presence of numerical chromosomal alterations, gene amplification, multinucleated cells and chromosome polysomy. ${ }^{9-15}$ The development of BCC is associated with aberrant activation of the Hedgehog $(\mathrm{HH})$ signalling pathway, which leads to increased expression and activation of glioma (GLI; GLI1 and GLI2) transcription factors, the principal

\footnotetext{
${ }^{1}$ Centre for Cutaneous Research, Blizard Institute, Barts and The London School of Medicine and Dentistry, Queen Mary University of London, London, UK; ${ }^{2}$ Imaging and Flow Cytometry Core Facilities, Blizard Institute, Barts and The London School of Medicine and Dentistry, Queen Mary University of London, London, UK; ${ }^{3}$ Centre for Molecular Oncology, Barts Cancer Institute, Barts and The London School of Medicine and Dentistry, Queen Mary University of London, London, UK; ${ }^{4}$ Pathology Core Facilities, Barts Cancer Institute, Barts and The London School of Medicine and Dentistry, Queen Mary University of London, London, UK and ${ }^{5}$ Department of Diagnostic and Oral Sciences, Blizard Institute, Barts and The London School of Medicine and Dentistry, Queen Mary University of London, London, UK ${ }^{*}$ Corresponding author: MP Philpott, Centre for Cutaneous Research, Blizard Institute, Barts and The London School of Medicine and Dentistry, Queen Mary University of London, 4 Newark Street, London E1 2AT, UK. Tel: +44 207882 7162; Fax: +44 207882 7171; E-mail m.p.philpott@qmul.ac.uk

${ }^{6}$ These authors contributed equally to this work.

Keywords: genomic instability; GLI2; BCC; aneuploidy; apoptosis; Bcl-2

Abbreviations: BCC, basal cell carcinoma; BCL-2, B-cell lymphoma 2; CIN, chromosomal instability; EGFP, enhanced green fluorescent protein; FACS, fluorescenceactivated cell sorting; GIN, genomic instability; GLI1, glioma 1; GLI2, glioma 2; GLI2 $\Delta \mathrm{N}, \mathrm{GLI} 2-\beta$ isoform, which lacks the N-terminal repressor domain; h/TERT, human telomerase reverse transcriptase; HH, Hedgehog; M-FISH, multiplex fluorescent in situ hybridisation; MTT, 3-(4,5-dimethylthiazol-2-yl)-2,5-diphenyl tetrazolium bromide; N/TERT, human telomerase-immortalised newborn epidermal keratinocyte; NHEK, normal human epidermal keratinocyte; pSIN, self-inactivating retroviral vector; SINCE, N/TERT keratinocytes stably expressing EGFP; SINEG2, N/TERT keratinocytes stably expressing EGFP-GLI2 $\Delta N$; SK-UT-1B, human uterus endometrium leiomyosarcoma; SNP, single nucleotide polymorphism

Received 07.8.13; revised 31.10.13; accepted 04.11.13; Edited by RA Knight
} 
effectors of the $\mathrm{HH}$ pathway. ${ }^{16}$ Targeted expression of an active mutant of GLI2 (GLI2 $\Delta \mathrm{N}-$ a constitutively active form of GLI2 isoform $\beta$, lacking the $\mathrm{N}$-terminal repressor domain) is sufficient to induce the formation of BCC-like lesions in the epidermis of transgenic mice ${ }^{17-19}$ and is required for their maintenance. ${ }^{20}$ Moreover, GLI2 is consistently upregulated in tumors that display complex genomic alterations. ${ }^{21-30}$ However, the role of GLI2 in GIN remains elusive. Therefore, we investigated whether GLI2 influences the genomic integrity of epidermal keratinocytes. We found that ectopic expression of GLI2 $\Delta \mathrm{N}$ profoundly affected the genomic stability of human epidermal keratinocytes, partly by suppressing cell cycle checkpoint proteins and disabling the intrinsic apoptotic mechanisms responsible for the elimination of cells with genomic alterations, thus identifying a novel role for GLI2 in tumorigenesis.

\section{Results}

Generation and characterisation of EGFP-GLI2 $\Delta \mathrm{N}$ stable expressing cells. Human telomerase-immortalised newborn epidermal (N/TERT) keratinocytes stably expressing enhanced green fluorescent protein (EGFP; SINCE) or enhanced green fluorescent protein-GLI2- $\beta$ isoform, which lacks the N-terminal repressor domain (EGFP-GLI2 $\Delta N$; SINEG2) were generated and expression of the fusion product was confirmed by mRNA expression, fluorescent microscopy, flow cytometry and western blot analysis (Supplementary Figure S1). The effect of GLI2 $\Delta \mathrm{N}$ on N/TERT cell proliferation was analysed by the Alamar blue and MTT (3-(4,5-dimethylthiazol-2-yl)-2,5-diphenyl tetrazolium bromide) cell viability assays, revealing significantly less SINEG2 cells compared with parental N/TERT or N/TERT keratinocytes stably expressing EGFP (SINCE) cells after 7 days in culture. Over prolonged culture (16 days), SINEG2 cells underwent fewer population doublings than either of the control cells. Collectively, these data show that ectopic GLI2 $\Delta \mathrm{N}$ reduces the proliferation rate of N/TERT cells (Supplementary Figure S2).

\footnotetext{
GLI2 induces tetraploidy and numerical chromosomal alterations. Cell cycle analysis after Hoescht-33342 staining revealed a significant increase in the $4 \mathrm{~N}$ population in SINEG2 (Supplementary Figure S3), which could be caused either by a G2/M block, or by an abnormal accumulation of tetraploid/near-tetraploid cells. The latter was confirmed by further analysis using propidium iodide, which showed that SINEG2 cells have a significant increase in the percentage of polyploid and aneuploid cells with $8 \mathrm{~N}$ and $>4 \mathrm{~N}$, compared with N/TERT and SINCE cells (Figures $1 a$ and $b$ ), indicating that GLI2 $\Delta \mathrm{N}$ expression promotes polyploidy and aneuploidy. Similarly, cell cycle analysis in primary normal human epidermal keratinocytes (NHEKs) and in human uterus endometrium leiomyosarcoma (SK-UT-1B) diploid cells, overexpressing GLI2 $\Delta \mathrm{N}$, showed a significant increase in the percentage of $4 \mathrm{~N}$ and $>4 \mathrm{~N}$ cells (Supplementary Figure S4). We also found enlarged, bi- and multinucleated SINEG2 cells by in situ Hoechst-33342 staining (Figure 1c), indicating the existence of binucleated tetraploid/near-tetraploid and
}

multinucleated polyploid and aneuploid cells, caused by cytokinesis failure.

Furthermore, we counted the proportion of binucleated N/TERT, SINCE and SINEG2 cells stained with DAPI and found a significantly $(P<0.01)$ elevated percentage of binucleated cells ( 19\%) in SINEG2 compared with both control cell lines (5.4\% for N/TERT and $4.2 \%$ for SINCE; Figure 1d). The difference in binucleated cells $(\sim 14 \%)$ is consistent with the differences in $4 \mathrm{~N}$ populations measured by flow cytometry $(\sim 11-15 \%)$ between control (N/TERT and SINCE) and SINEG2 keratinocytes (Supplementary Figure S3 and Figure 1a), suggesting that the accumulation of 4N SINEG2 cells, observed by flow cytometry, is mainly due to the presence of tetraploid/near-tetraploid cells rather than the activation of the G2/M checkpoint of diploid cells. This is further supported by the $8 \mathrm{~N}$ and $>4 \mathrm{~N}$ DNA content cells (Figures 1a and c). However, a transient arrest of cells, due to activation of the mitotic spindle checkpoint, cannot be excluded completely.

GLI2 induces structural chromosomal abnormalities. We also revealed structural chromosomal abnormalities in GLI2 $\Delta \mathrm{N}$-expressing keratinocytes. Multiplex fluorescent in situ hybridisation (M-FISH) analysis revealed a stable karyotype of $47, X Y,+20$, therefore with the presence of an extra chromosome 20 (trisomy 20) in the near-diploid male, accounting for $\sim 90 \%$ of metaphases analysed from keratinocyte cell lines N/TERT and SINCE (Figure 2a). The rest were tetraploid cells with double number of each chromosome in the near-diploid cells. Trisomy 20 was further confirmed by $10 \mathrm{~K}$ SNP (single nucleotide polymorphism) array analyses (GEO accession number: GSE36105), using normal donor human skin keratinocytes as reference cells (Supplementary Figure S5). No structural chromosome aberrations were detected in the control N/TERT and SINCE cells (Figure 2).

However, SINEG2 keratinocytes showed both numerical and structural chromosome aberrations (Figure 2). Approximately $14 \%$ of metaphase SINEG2 cells were tetraploid (94 chromosomes with the karyotype 94, XXYY, +20×2; Figure $2 b$ ) and $\sim 70 \%$ were near-tetraploid/aneuploid cells with random gains and losses of chromosomes (i.e., 73 chromosomes; Figure 2c), in contrast to control cells of which only $\sim 10 \%$ were tetraploid. Interestingly, we found structural chromosomal rearrangements in $\sim 29 \%$ (4/14) karyotyped metaphases of SINEG2 keratinocytes, including a clonal non-reciprocal chromosome translocation; $t(7 ; 14)$ in 3 of 14 karyotyped metaphases (Figures $2 d$ and e), 1 is diploid (Figure $2 \mathrm{~d}$ ) and the other 2 are near-tetraploid/aneuploid cells (Figure 2e). A non-clonal unbalanced translocation $\mathrm{t}(9 ; 14)$ was also detected in a near-tetraploid/aneuploid SINEG2 keratinocyte (data not shown).

GLI2 $\Delta \mathrm{N}$ induction leads to impaired checkpoint control and apoptosis for the survival of cells with chromosomal abnormalities. Cells with numerical or structural chromosome changes usually stimulate cell cycle

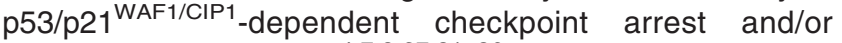
subsequent apoptosis. $4,7,8,27,31-36$ To understand how such populations are maintained, we investigated whether, 
a
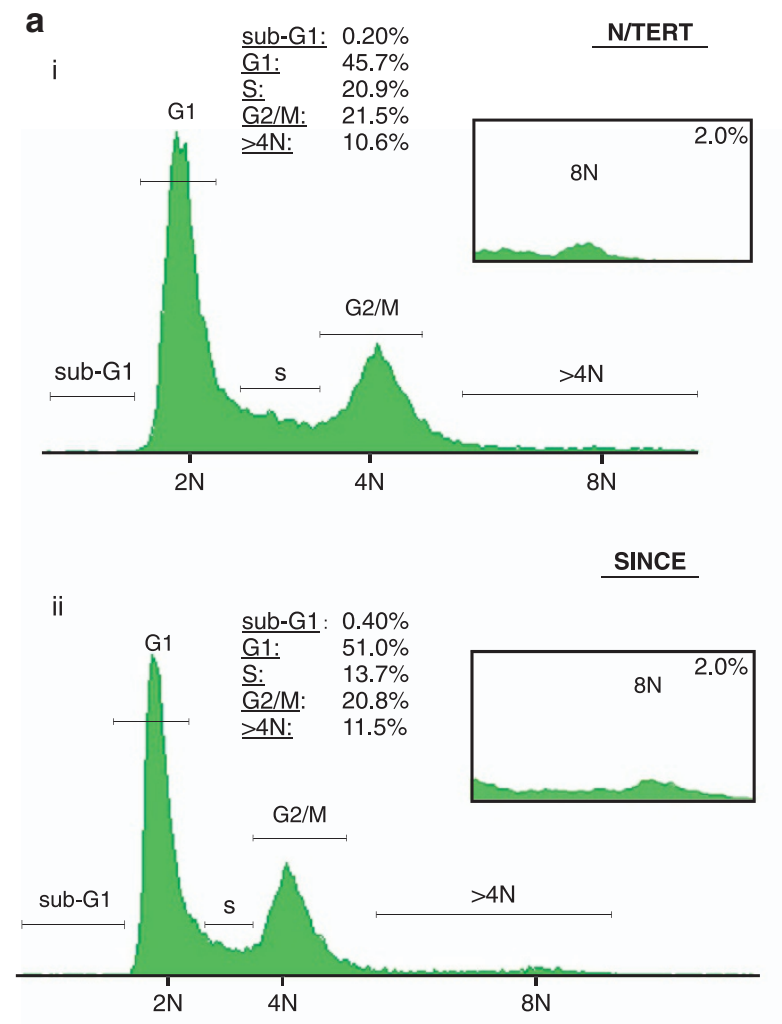

SINEG2

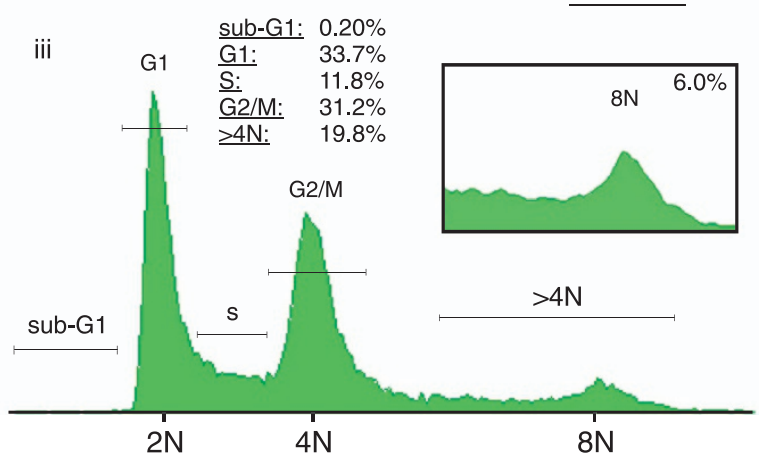

b i
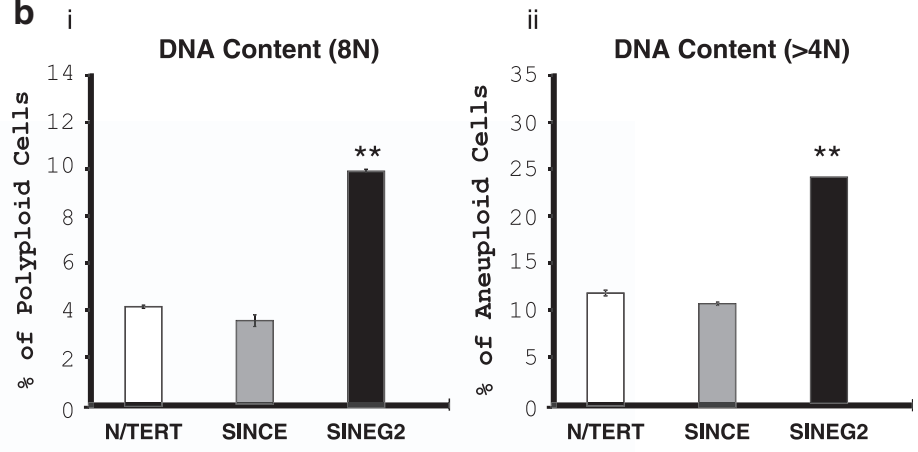

C

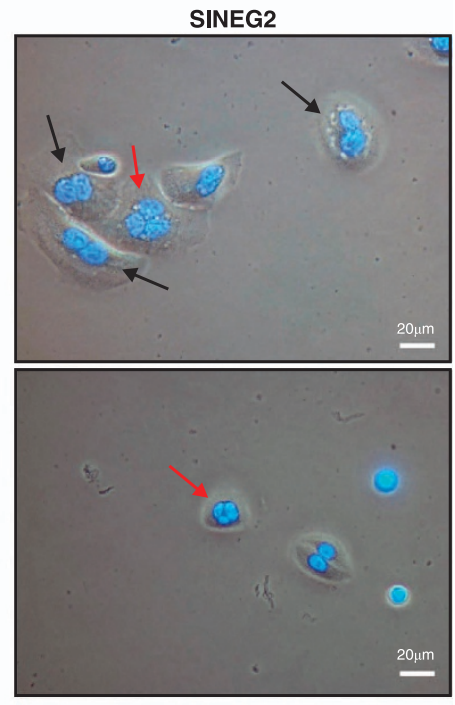

d

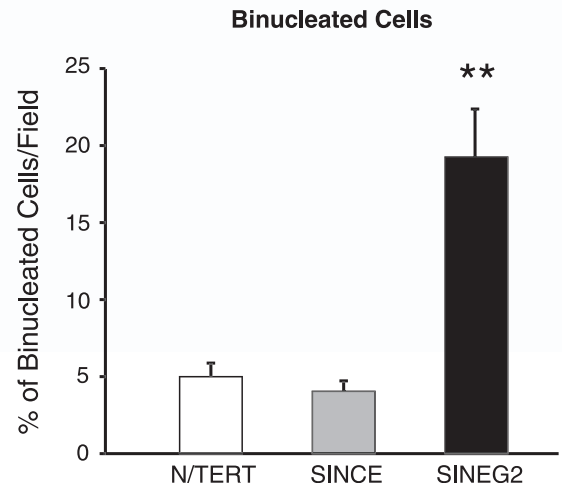

Figure 1 GLI2 $\Delta N$ induces tetraploidy, polyploidy and aneuploidy in N/TERT keratinocytes. (a) Propidium iodide staining, followed by flow cytometry analysis to obtain cell cycle distribution of N/TERT (i), SINCE (ii) and SINEG2 (iii) cells. Sub-G1 trace was negligible for all cell lines examined. Data are representative of three independent experiments. (b) Graphical representation of the percentage of (i) $8 \mathrm{~N}$ and (ii) $>4 \mathrm{~N}$ cells for each cell line after Hoechst-33342 staining and flow cytometry analysis. SINEG2 cells have significantly higher $(P \leq 0.01)$ percentage of polyploid and aneuploid cells in culture. Each bar represents the mean values $\pm S$.E.M. of duplicate samples. (c) Representative pictures taken from Hoechst-33342-stained SINEG2 cell line at $\times 20$ magnification, showing the presence of bi- and multinucleated cells. Black arrows indicate binucleated cells and red arrows indicate multinucleated cells. DNA was detected by Hoechst-33342 staining (blue). (d) N/TERT, SINCE and SINEG2 cells were stained with DAPI to visualise nuclear DNA. SINEG2 cells display a significant increase ( $\sim 3.5$ fold) in the population of binucleated (tetraploid/near-tetraploid) cells. Each bar represents the mean values of binucleated cells per field \pm S.E.M. of 7 fields for N/TERT and SINCE, and 13 fields for SINEG2. Total count $\sim 300$ cells per cell line. ${ }^{* *} P \leq 0.01$. N, haploid number

along with the generation of cells with accumulated genomic alterations, GLI2 $\Delta \mathrm{N}$ also prevents the induction of the 'tetraploidy checkpoint' and apoptosis.

Although we detected a marginal increase of p53 protein levels in SINEG2 keratinocytes (Figure 3a), its direct transcriptional target $\mathrm{p} 21^{\mathrm{WAF} 1 / \mathrm{CIP} 1}$ was significantly downregulated (Figure $3 b$ ), indicating a defective $\mathrm{G} 1$ 'tetraploidy checkpoint' in GLI2 $\Delta \mathrm{N}$-expressing cells. This demonstrates the ability of $\mathrm{GLI} 2 \Delta \mathrm{N}$ to suppress $\mathrm{p} 21^{\mathrm{WAF} 1 / \mathrm{CIP} 1}$ in a p53-independent manner. p21 WAF1/CIP1 was also found to 
a

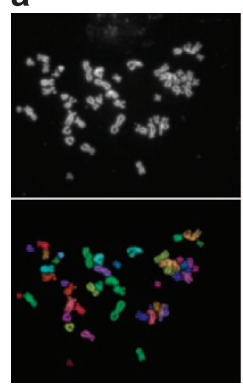

c

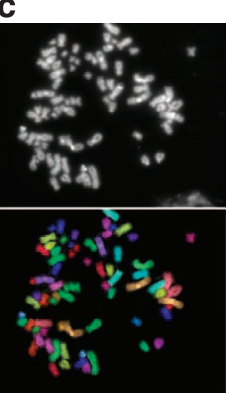

e

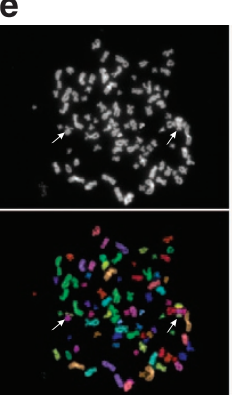

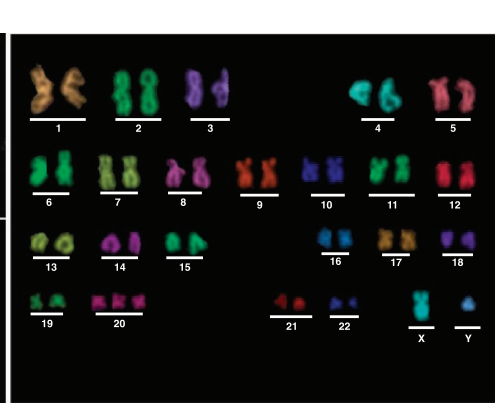

b

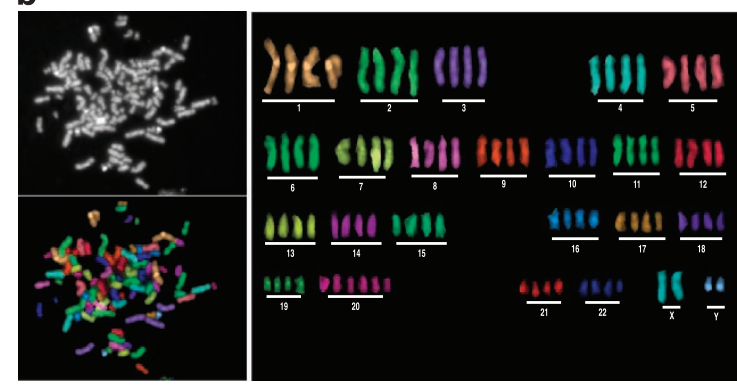

d
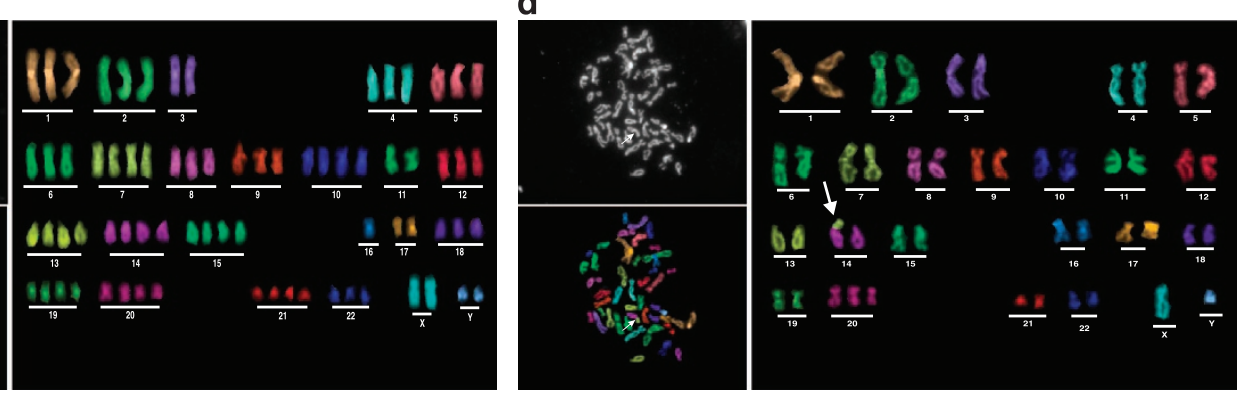

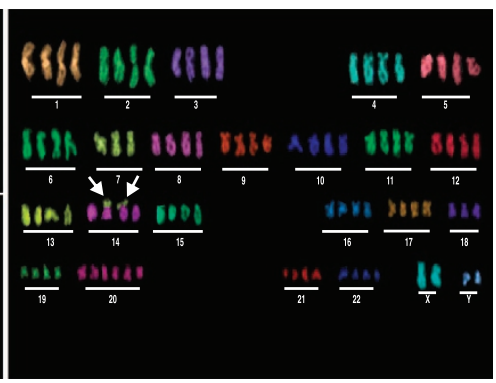

Figure 2 GLI2 $\triangle N$ induces numerical and structural chromosomal changes in human keratinocytes. (a) Representative metaphase cell from SINCE as a DAPI-counterstained image (upper left), with the 24-colour-painted chromosomes (lower left) and a karyotype of 47, XY, +20 , based on the colour code (right). (b) Representative tetraploid metaphase cell from SINEG2 as a DAPI-counterstained image (upper left), with the 24-colour-painted chromosomes (lower left) and a karyotype of $94, X X Y Y,+20 \times 2$ based on the colour code (right). (c) Metaphase aneuploid (near-tetraploid aneuploid) SINEG2 cell as a DAPI-counterstained image (upper left), with the 24-colour-painted chromosomes (lower left) and a karyotype of 73 , XXYY, $-1,-2,-3 \times 2,-4,-5,-6,-8,-9,-11 \times 2,-12,-16 \times 3,-17 \times 2,-18$ and -22 , based on the colour code (right). This is an example of a tetraploid cell that might have undergone multipolar and asymmetric divisions, yielding aneuploid progenies. (d) Diploid SINEG2 metaphase cell with the clonal nonreciprocal unbalanced translocation $\mathrm{t}(7 ; 14$; white arrows) as a DAPI-counterstained image (upper left), with the 24-colour-painted chromosomes (lower left) and a karyotype of 47, XY, $-7,+$ del7q, $-14,+\operatorname{der}(14) t(7 ; 14),+20$, based on the colour code (right). (e) Representative near-tetraploid SINEG2 metaphase cell with the clonal nonreciprocal unbalanced translocation $\mathrm{t}(7 ; 14$; white arrows; upper left), with the 24-colour-painted chromosomes (lower left) and a karyotype of $92, \mathrm{XXYY},-7 \times 2,+$ del7q, $-14 \times 2,+\operatorname{der}(14) t(7 ; 14) \mathrm{X} 2,-18,+20 \times 2$, based on the colour code (right)

be suppressed in human BCCs, which are GLI2-driven tumors sharing many attributes with the GLI2 $\Delta \mathrm{N}$-expressing keratinocytes (Supplementary Figure S6). 14-3-3 $\sigma$, another direct transcriptional target of p53 after DNA damage and lost in BCCs, ${ }^{37}$ was also downregulated in SINEG2 compared with both N/TERT and SINCE keratinocytes (Figure 3c).

Following Annexin V staining, flow cytometry analysis showed that upon expression of GLI2 $\Delta \mathrm{N}$, despite the presence of GIN, there was no difference in numbers of live, early apoptotic, late apoptotic/dead cells, between control and SINEG2 cells (Figure 3d), indicating lack of apoptosis induced by genomic changes in $\mathrm{GLI} 2 \Delta \mathrm{N}$-expressing cells.

B-cell lymphoma 2 (BCL-2) is a direct target of GLI2 $\Delta \mathrm{N}$ in $\mathrm{HaCaT}$ keratinocytes and is highly expressed in human BCCs. ${ }^{38}$ We found that the level of BCL-2 mRNA was elevated by 11-fold in SINEG2 compared with N/TERT and
SINCE controls ( $P \leq 0.01$; Figure $3 e)$, whereas Bcl-2 protein (Figure 3f) was massively upregulated in SINEG2 cells, suggesting a role in preventing apoptosis in SINEG2 cells.

As GLI2 $\Delta \mathrm{N}$-expressing cells are resistant to tetraploidymediated apoptosis, we investigated whether GLI2 overexpression can also render cells resistant to other apoptotic stimuli such as UV light, which is known to cause p53-mediated induction of p2 $1^{\mathrm{WAF} 1 / \mathrm{CIP} 1}$ and apoptosis. UVB irradiation is an established risk and aetiological factor in human BCC formation. Following UVB irradiation, p53 was upregulated in both GLI2 $\Delta \mathrm{N}$-expressing and control keratinocytes (Figure 4a). However, p21 $1^{\text {WAF1/CIP1 }}$ was upregulated only in control cells (Figure 4a) but remained suppressed in SINEG2 cells (Figure 4a), further confirming that GLI2 suppresses p21 expression independently of p53. The apoptotic response of N/TERT, SINCE and SINEG2 cells 
a

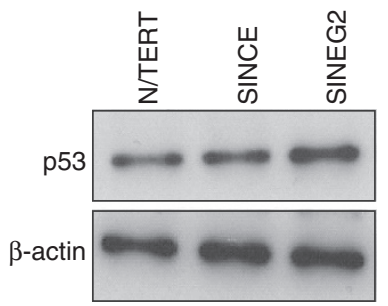

d

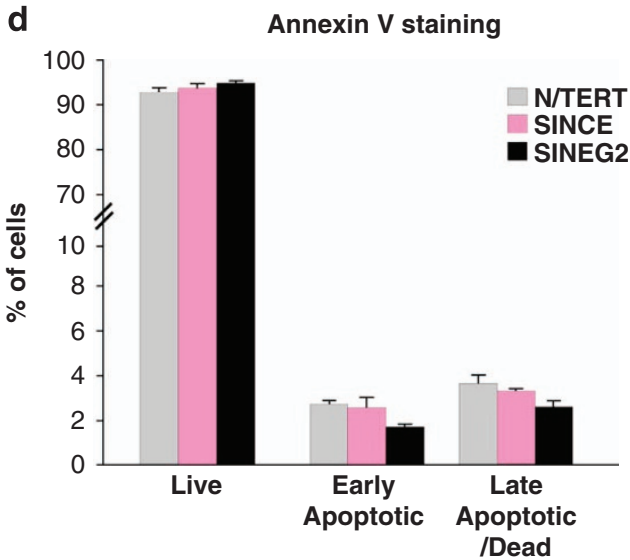

b
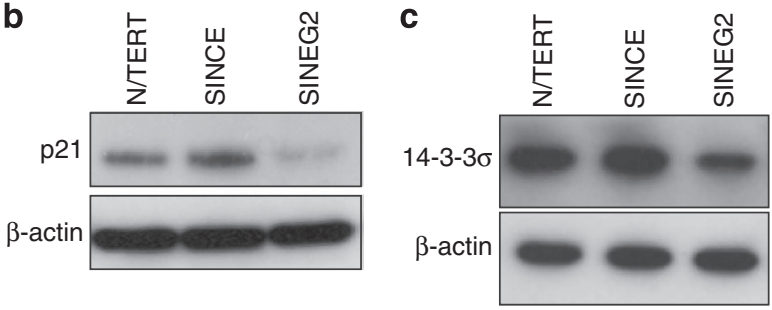

f

e

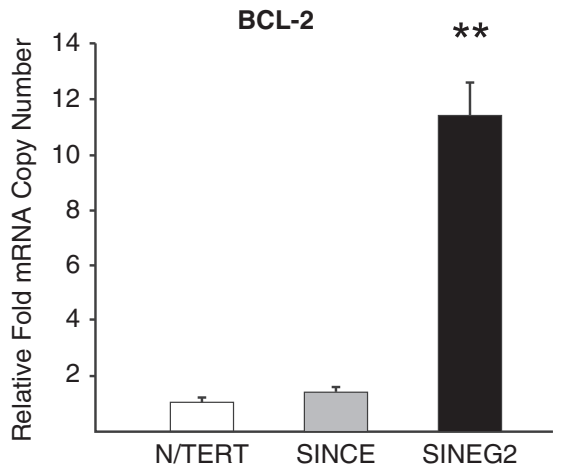

Figure 3 GLI2 $\Delta N$ expression abolishes cell cycle checkpoints and induces anti-apoptotic signalling. SINEG2 cells show a marginal increase of p53 protein (a), a significant decrease of the CDK inhibitor p21 ${ }^{\text {WAF1/CIP1 }}$ protein (b) and a marked decrease in the 14-3-3 $\sigma$ protein levels (c), compared with both N/TERT and SINCE control cells. $\beta$-Actin was used as a protein-loading control. (d) N/TERT, SINCE and SINEG2 cells stained with Cy5 Annexin V and DAPI for the detection of apoptotic and dead cells, respectively. The percentage of cells representing the early (Annexin V $(+)$ DAPI $(-)$ ) and late (Annexin V $(+)$ DAPI $(+)$ ) apoptotic or dead populations show no significant differences. Each bar represents the mean values \pm S.E.M. of three independent experiments, each of which consisted of duplicate samples. BCL-2 is upregulated in SINEG2 cells both at RNA (e) and protein (f) level, compared with N/TERT and SINCE control cells. In e, each bar represents mean fold induction/or suppression relative to N/TERT (arbitrary value of 1$) \pm$ S.E.M. of triplicate samples. ${ }^{*} P \leq 0.01$

following UVB irradiation (10 or $30 \mathrm{~mJ} / \mathrm{cm}^{2}$ ) was measured against mock-irradiated controls $\left(0 \mathrm{~mJ} / \mathrm{cm}^{2}\right)$. SINEG2 display a reduction of early apoptotic and late apoptotic/dead cells in response to high $\left(30 \mathrm{~mJ} / \mathrm{cm}^{2}\right)$ dose of UVB irradiation $(\sim 9 \%$ early apoptotic cells), compared with both N/TERT ( $\sim 24 \%$ early apoptotic cells) and SINCE ( $\sim 24 \%$ early apoptotic cells) control keratinocytes (Figure 4b). Similar results were obtained with a lower $\left(10 \mathrm{~mJ} / \mathrm{cm}^{2}\right)$ UVB dose $(P<0.001$; Figure 4c). Furthermore, the absence of activated/cleaved Caspase-3 (Figure 4d), in combination with the high-level of Bcl-2 (Figure 4d), further confirm that SINEG2 keratinocytes are able to escape p53-mediated apoptosis.

Inhibition of BCL-2 restores endogenous (chromosomal alterations) and exogenous (UVB) DNA-damage-induced apoptosis to GLI2 $\Delta \mathrm{N}$-expressing keratinocytes. Activation of the anti-apoptotic signalling is essential for the survival of cells with endogenous (i.e., GIN) or exogenous (i.e., UVB) DNA damage, and is one of the mechanisms employed by cancer cells to evade apoptosis. Our results suggest a pivotal role for BCL-2 in the survival of cells overexpressing GLI2 $\triangle N$. We inhibited BCL-2 in N/TERT, SINCE and SINEG2 keratinocytes using a range of concentrations of Navitoclax (ABT-263), and measured apoptosis by Annexin V staining and cleavage of Caspase-3. Navitoclax is a potent inhibitor of the $\mathrm{Bcl}-2 / \mathrm{Bcl}-\mathrm{xL}$ proteins, which restores the intrinsic pathway activity in response to apoptotic stimuli. ${ }^{39,40}$ By Annexin $\mathrm{V}$ flow cytometry analysis, we show that SINEG2 cells become highly sensitised to low and high doses of Navitoclax (Figure 5a and Supplementary Figure S7A), which correlates with the increased cleavage of Caspase-3 protein (Figure 5b (iii) and Supplementary Figure S7B), which occurred even at the low dose of $0.1 \mu \mathrm{M}$ of Navitoclax (Figure 5b (iii)). In contrast, normal N/TERT and SINCE control cells required at least a minimum dose of $5 \mu \mathrm{M}$ before Caspase-3 protein cleavage becomes detectable (Figure $5 \mathrm{~b}$ (i and ii) and Supplementary Figure S7B), suggesting lower apoptotic induction of normal human keratinocytes to BCL-2 inhibition compared with GLI2 $\Delta \mathrm{N}$-expressing keratinocytes.

To determine whether the resistance of GLI2 $\Delta \mathrm{N}$-expressing cells to UVB-induced apoptosis can be attributed to the elevated levels of BCL-2, we investigated the effects of Navitoclax on apoptosis of SINEG2 cells in response to UVB $\left(30 \mathrm{~mJ} / \mathrm{cm}^{2}\right)$. Much lower doses of Navitoclax (ABT-263; $0.001-0.25 \mu \mathrm{M}$ ) were used due to possible synergistic effects with UVB. Annexin V staining (Figure $5 \mathrm{c}$ (i)) and immunoblotting analysis (Figure $5 d$ and Supplementary Figure S7C) showed that SINEG2 cells retain their resistance to UVB-induced apoptosis, during treatment with very low doses of Navitoclax (0.001-0.01 $\mu \mathrm{M})$, compared with N/TERT and SINCE control cells. These doses of the drug may be insufficient to fully inhibit the function of BCL-2, especially in SINEG2 cells where the basal levels of BCL-2 protein are dramatically elevated. Consistently, at higher doses of Navitoclax $(>0.01 \mu \mathrm{M})$, the number of apoptotic SINEG2 cells rises sharply and surpasses that of N/TERT and SINCE cells $(0.05-0.25 \mu \mathrm{M}$; 
a

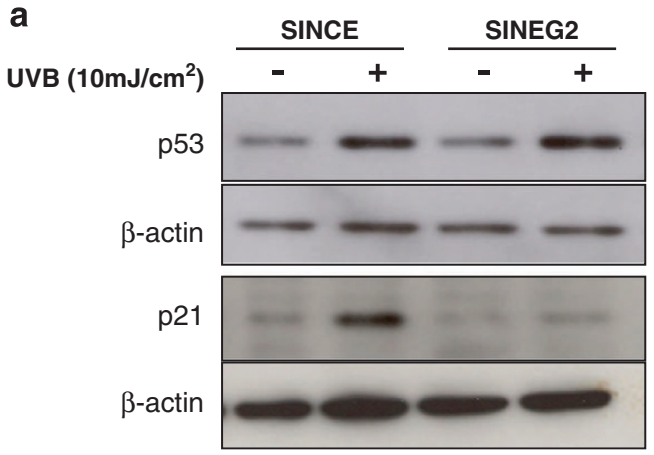

C

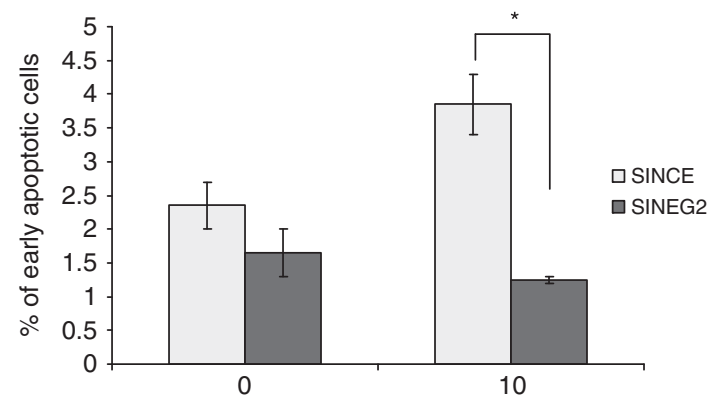

UVB $\left(\mathrm{mJ} / \mathrm{cm}^{2}\right)$ b

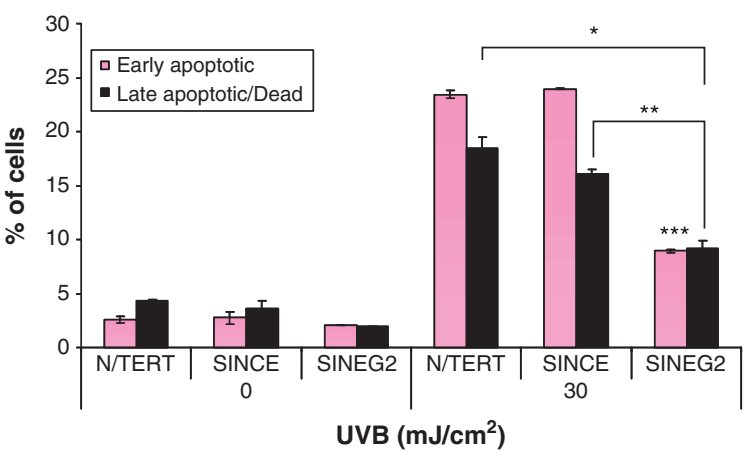

d

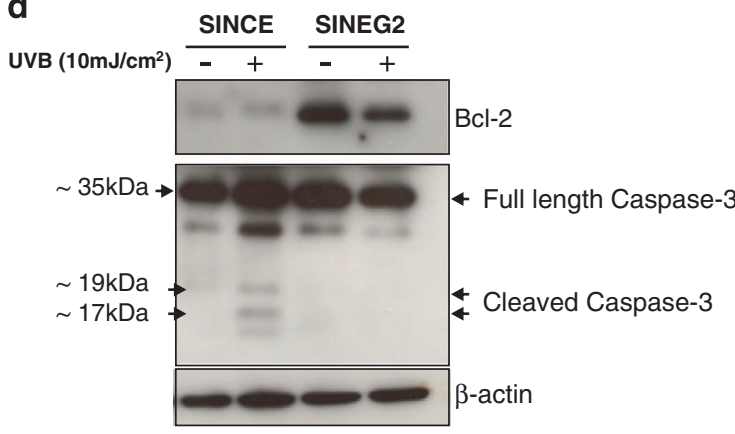

Figure 4 GLI2 $\Delta \mathrm{N}$-expressing keratinocytes escape the UVB DNA damage response by p53-independent downregulation of p21 and display resistance to UVB-mediated apoptosis. (a) Immunoblotting analysis for p53 and p21 on UV $(+)$ and non-UV ( - ) SINCE and SINEG2 whole-cell lysates. p53 is upregulated in SINCE control and SINEG2 cells on UVB exposure, whereas p21 is only increased in control cells but not in GLI2 $\Delta N$-expressing cells after UVB. (b) N/TERT, SINCE and SINEG2 keratinocytes either mock treated $\left(0 \mathrm{~mJ} / \mathrm{cm}^{2}\right)$ or UVB irradiated with $30 \mathrm{~mJ} / \mathrm{cm}^{2}$. SINEG2 keratinocytes display a reduction in the percentage of early and late apoptotic/dead populations in response to high dose of UVB irradiation compared with both N/TERT and SINCE control keratinocytes. Each bar represents the mean values \pm S.E.M. of duplicate samples. ${ }^{*} P \leq 0.05,{ }^{* *} P \leq 0.01,{ }^{* *} P \leq 0.001$. (c) SINCE and SINEG2 keratinocytes, either mock $\left(0 \mathrm{~mJ} / \mathrm{cm}^{2}\right)$ or UVB $\left(10 \mathrm{~mJ} / \mathrm{cm}^{2}\right)$ treated. It shows that SINEG2 cells are less susceptible to UVB-induced early apoptosis compared with SINCE control cells. Each bar represents mean values \pm S.E.M. of duplicate samples. ${ }^{*} P \leq 0.05$. (d) SINCE and SINEG2 keratinocytes were collected for total protein, $24 \mathrm{~h}$ after UVB $10 \mathrm{~mJ} / \mathrm{cm}^{2}(+)$ or mock $(-) 0 \mathrm{~mJ} / \mathrm{cm}^{2}$ treatment. Total protein extracts were immunoblotted against anti-Bcl-2 ( $\sim 26 \mathrm{kDa}$; top panel) and anti-full length $(\sim 35 \mathrm{kDa})$, and cleaved Caspase-3 $(\sim 19,17 \mathrm{kDa}$; middle panel) antibodies. $\beta$-Actin $(\sim 42 \mathrm{kDa})$ was used as a proteinloading control. The absence of activated (cleaved) Caspase-3 in SINEG2 cells, a late apoptotic marker, following UVB irradiation, confirms the apoptotic resistance of SINEG2 keratinocytes compared with SINCE cells

Figure 5c), again indicating increased induction of apoptotic cell death in SINEG2 cells. Immunoblotting analysis showed that the cleavage of Caspase-3 at doses $>0.01 \mu \mathrm{M}$ (i.e., $0.05 \mu \mathrm{M}$ ) was higher in SINEG2 than in N/TERT and SINCE control cells (Figure 5d and Supplementary Figure S7C).

Our results indicate that the survival of GLI2 $\Delta \mathrm{N}$-expressing cells largely depends on BCL-2. Once its function is pharmacologically inhibited, cells become hyper-sensitised to apoptotic cell death. As tetraploidy/aneuploidy itself is a strong apoptotic signal, blocking the function of BCL-2 is expected to induce a marked apoptotic response and the reduction of abnormal tetraploid/aneuploid progenies. We tested this hypothesis by treating SINEG2 cells with a range of doses of BCL-2 inhibitor Navitoclax (ABT-263) before examining their DNA content profile. As expected, treatment over a range of concentrations of Navitoclax induced much higher levels of apoptosis in SINEG2 cells, detectable by DNA fragmentation (sub-G1; Figures $6 a$ and b (i)), compared with normal control N/TERT and SINCE cells (Supplementary Figure S7D). The numbers of cells with DNA content $4 \mathrm{~N}$
(G2/M normal diploid cells and tetraploid/near-tetraploid G1 cells), as well as those with DNA content $>4 \mathrm{~N}$ (polyploid and aneuploid cells), also decreased with increasing concentrations of Navitoclax. By quantifying the numbers of cells in each group, we observed that cells with DNA content of $4 \mathrm{~N}$ and those with DNA content $>4 \mathrm{~N}$ were most significantly affected by treatment with Navitoclax (Figure 6b).

The fact that N/TERT and SINCE cells are not equally sensitised to BCL-2 inhibition compared with SINEG2 cells suggests that the tetraploid and near-tetraploid G1 SINEG2 cells $(4 N)$ may be more sensitive to $B C L-2$ inhibition than the diploid G2/M cells (also $4 \mathrm{~N}$ ), due to apoptosis induced by genomic changes. Interestingly, the number of S-phase cells is also gradually elevated with increasing doses of the drug in SINEG2 cells (Figure 6b) compared with that in N/TERT and SINCE normal diploid control cells (Supplementary Figure S7D). This population represents cells with a possible S-phase arrest and/or 4N cells with fragmented DNA due to apoptosis. As the normal control N/TERT and SINCE cells do not show any evidence of S-phase arrest (Supplementary Figure S7D), the 


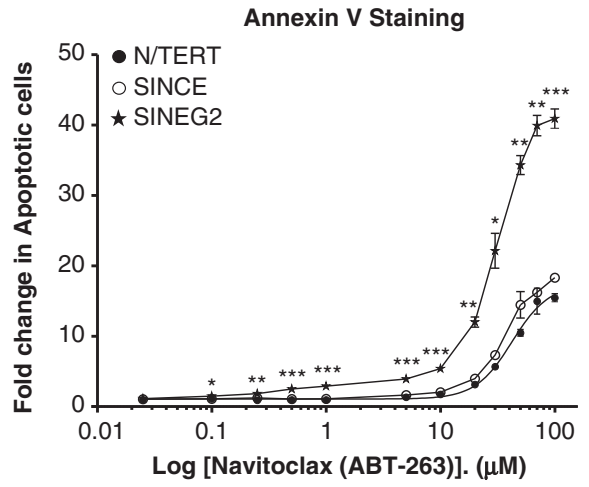

b i

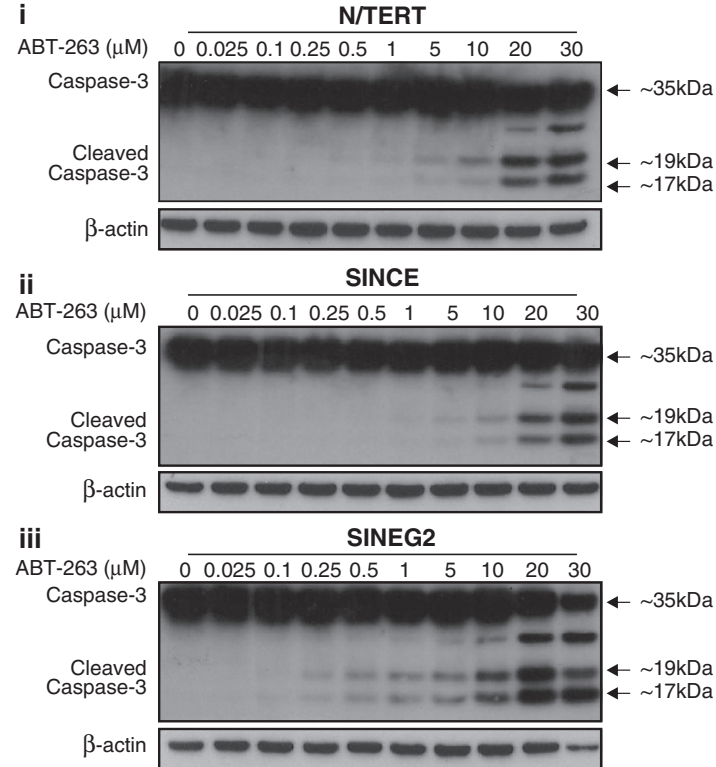

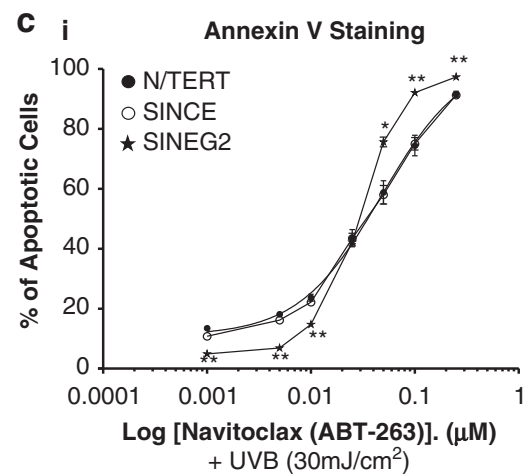

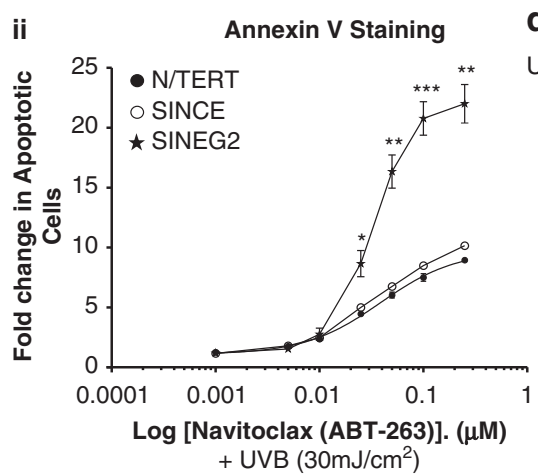

d

UVB $\left(30 \mathrm{~mJ} / \mathrm{cm}^{2}\right)+\quad+\quad+$ ABT-263 $(\mu \mathrm{M}) \quad 0 \quad 0.01 \quad 0.05$

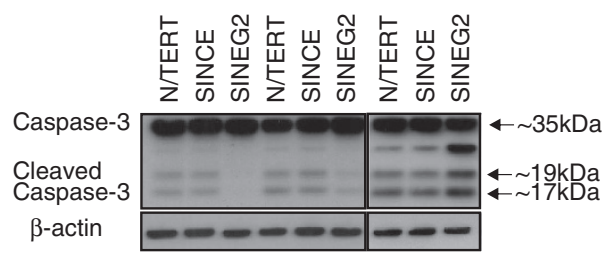

+ UVB $\left(30 \mathrm{~mJ} / \mathrm{cm}^{2}\right)$

Figure 5 BCL-2 inhibition leads to apoptosis sensitisation of GLI2 $\triangle \mathrm{N}$-expressing cells and abolishes their resistance to UVB-mediated apoptosis. (a) N/TERT, SINCE and SINEG2 cells were either untreated $(0 \mu \mathrm{M} / \mathrm{DMSO})$ or treated with increasing concentrations of Navitoclax (ABT-263; $0.025-100 \mu \mathrm{M})$ and were incubated for $24 \mathrm{~h}$. Next, apoptosis was detected by Cy5 Annexin V and DAPI staining, followed by flow cytometry analysis showing that SINEG2 cells have much higher apoptotic sensitivity to BCL-2 inhibition compared with control cells. Each point represents the mean fold change in the number of early (Annexin V $(+) \operatorname{DAPI}(-))$ and late $(\operatorname{Annexin~V~}(+)$ DAPI $(+))$ apoptotic cells relative to the treatment with vehicle-only $(0 \mu \mathrm{M} / \mathrm{DMSO})$ control for each individual cell line (arbitary value 1$) \pm S$.E.M. of duplicate samples. ${ }^{*} P \leq 0.05$, ${ }^{* *} P \leq 0.01,{ }^{* *} P \leq 0.001$. (b(i)) N/TERT, (ii) SINCE and (iii) SINEG2 cells were either untreated ( $0 \mu \mathrm{M} / \mathrm{DMSO}$ ) or treated with increasing doses of Navitoclax (ABT-263; $0.025-$ $30 \mu \mathrm{M})$ and were incubated for $24 \mathrm{~h}$. Next, cells were collected and whole-cell lysates were prepared and immunoblotted against anti-full-length Caspase $3(\sim 35 \mathrm{kDa})$ antibody, whereas $\beta$-actin $(\sim 42 \mathrm{kDa}$ ) was used as a protein-loading control. Apoptosis was assessed through detecting the cleaved bands of Caspase-3 ( 19, $17 \mathrm{kDa})$. In c and d, N/TERT, SINCE and SINEG2 cells were either untreated (0 $\mu \mathrm{M} / \mathrm{DMSO})$ or treated with different concentrations of Navitoclax (ABT-263; 0.001-0.25 $\mu \mathrm{M})$ for up to $24 \mathrm{~h}$. Cells were irradiated with a single dose of $30 \mathrm{~mJ} / \mathrm{cm}^{2}$ and were allowed to grow for another $\sim 20 \mathrm{~h}$. Next, apoptosis was detected either by (c) Cy5 Annexin V and DAPI staining, followed by flow cytometry analysis or by (d) immunoblotting analysis, showing that inhibition of BCL-2 abolishes the resistance of GLI2 $\triangle N$-expressing cells to UVBinduced apoptosis. (c(i)) Each point represents the mean values/percentages of early (Annexin V $(+)$ DAPI $(-))$ and late $($ Annexin V $(+)$ DAPI $(+))$ apoptotic cells \pm S.E.M. of three independent experiments. ${ }^{*} P \leq 0.05$, ${ }^{*} P \leq 0.01$; (ii) each point represents the mean fold change in the number of early $($ Annexin $V(+) D A P I(-))$ and late (Annexin V (+) DAPI (+)) apoptotic cells relative to the treatment with vehicle-only $(0 \mu \mathrm{M} / \mathrm{DMSO})$ and $30 \mathrm{~mJ} / \mathrm{cm}^{2} \mathrm{UVB}$ control for each individual cell line (arbitary value 1) \pm S.E.M. of three independent experiments. ${ }^{*} P \leq 0.05$, ${ }^{* *} P \leq 0.01$, ${ }^{* * *} P \leq 0.001$. (d) Whole-cell lysates were prepared and immunoblotted against anti-full-length Caspase 3 $(\sim 35 \mathrm{kDa})$ antibody, whereas $\beta$-actin $(\sim 42 \mathrm{kDa})$ was used as a protein-loading control

increased number of SINEG2 cells in S phase may consist mainly of apoptotic tetraploid and near-tetraploid G1 cells $(4 \mathrm{~N})$. The number of cells with DNA content 2N (G1) appears to be stable across treatment with different doses of Navitoclax and only shows a significant decrease at 20 and $30 \mu \mathrm{M}$ of Navitoclax (Figure 6b). However, this reduction in cell number is less than that seen for cells with DNA content $4 \mathrm{~N}$ and $>4 \mathrm{~N}$. Collectively, we showed that inhibition of BCL-2 function by Navitoclax affects the survival of genomically unstable tetraploid/aneuploid SINEG2 cells more than stable diploid cells.

\section{Discussion}

GLI2 is frequently overexpressed in human cancers associated with aneuploidy and CIN, including human BCCs, prostate, breast, hepatocellular, colon and oral squamous cancers, osteosarcomas and melanomas. $5,10,12,21-30,38,41-44$ However, its role in aneuploidy and CIN has not previously been reported. In this study we showed that stable overexpression of the constitutively active form of GLI2 in N/TERT human epidermal keratinocytes resulted in the accumulation and increased viability of cells with both numerical 
a i

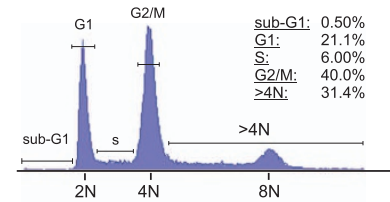

ii

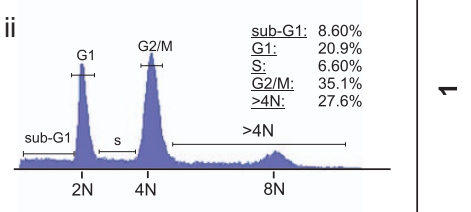

iii

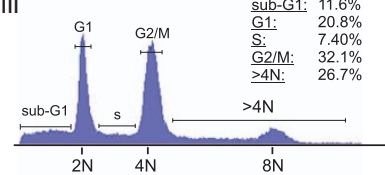

iv

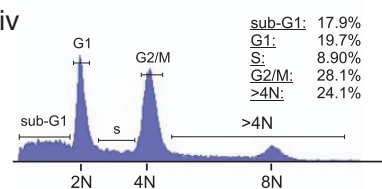

V

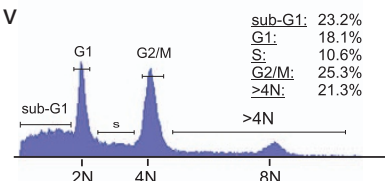

vi

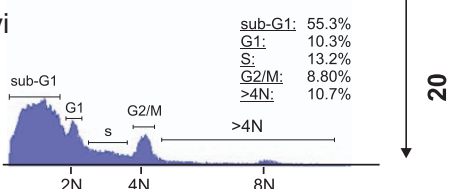

0

$\stackrel{2}{0}$

急 b

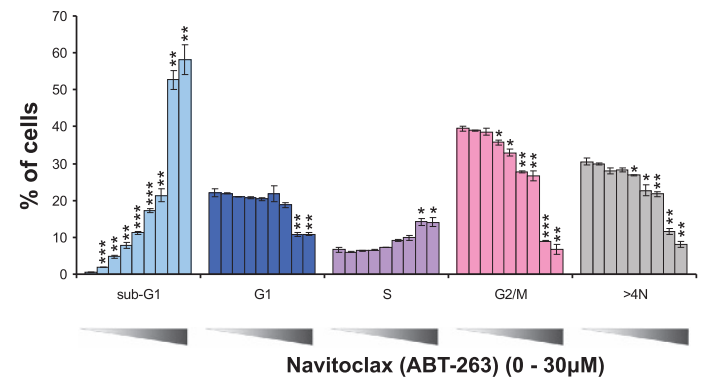

ii

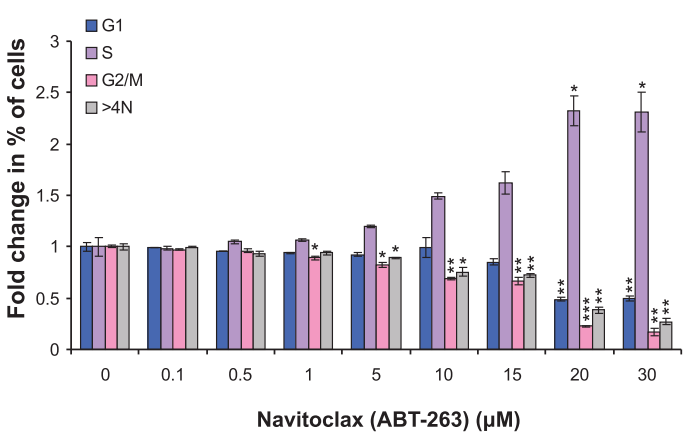

Figure 6 BCL-2 inhibition leads to the induction of apoptosis and reduction of abnormal tetraploid and aneuploid cells in SINEG2 cultures. SINEG2 cells were either untreated $(0 \mu \mathrm{M} / \mathrm{DMSO})$ or treated with increasing concentrations of Navitoclax (ABT-263; $0.1-30 \mu \mathrm{M}$ ) and were incubated for $24 \mathrm{~h}$. Next, cells were stained with propidium iodide (PI) followed by flow cytometry analysis to obtain cell cycle distribution of SINEG2 cells. (a) DNA content profiles of SINEG2 cells after treatment with various doses of Navitoclax (ABT-263) (i-vi). Data are representative of three independent experiments, each of which consisted of duplicate samples. N, haploid number. (b) Graphical representations of flow cytometry analysis; (i) each bar represents the mean values/percentages of SINEG2 cells \pm S.E.M. of duplicate samples present in each different phase of the cell cycle (apoptotic sub-G1, G1, S, G2/M, DNA content $>4 \mathrm{~N}$ ). ${ }^{*} P \leq 0.05,{ }^{* *} P \leq 0.01,{ }^{* \star *} P \leq 0.001$. Black arrow represents the increasing doses of Navitoclax (ABT-263; 0/DMSO, 0.1, 0.5, 1, 5, 10, 15, 20,30 $\mu \mathrm{M}$ ); (ii) each bar represents the mean fold change in the number of treated SINEG2 cells relative to the treatment with vehicle-only $(0 \mu \mathrm{M} / \mathrm{DMSO})$ control for each different phase of the cell cycle (G1, S, G2/M, DNA content $>4 \mathrm{~N}$; arbitary value 1$) \pm S$.E.M. of duplicate samples. ${ }^{*} P \leq 0.05$, ${ }^{* *} P \leq 0.01,{ }^{* * *} P \leq 0.001$

and structural chromosomal alterations, revealing potential novel mechanisms by which GLI2 might exert its tumorigenic effect.

Cell cycle analysis of N/TERT keratinocytes expressing GLI2 $\Delta N$ showed that cells displayed an increased percentage of $4 \mathrm{~N}$ cells, including many binucleated tetraploid cells of $\mathrm{G} 1$ biochemical state, as well as an increased proportion of polyploid and aneuploid cells with DNA content $8 \mathrm{~N}$ and $>4 \mathrm{~N}$ representing G2/M- and S-phase tetraploid/near-tetraploid aneuploid cells. These findings indicate that overexpression of $\mathrm{GLI} 2 \Delta \mathrm{N}$ can interfere with normal cell cycle completion. This effect is not cell line specific, as we observed similar effects when GLI2 $\Delta \mathrm{N}$ was overexpressed in NHEK and in the diploid tumorigenic line SK-UT-1B. Moreover, the increase in tetraploid cells observed on GLI2 $\Delta \mathrm{N}$ induction may be a contributing factor in cell transformation and carcinogenesis, by promoting GIN/CIN and the formation of aneuploid cells. ${ }^{6,33}$ Tetraploidy is commonly seen in human cancer, including GLI2 $\Delta \mathrm{N}$-driven malignancies, such as BCCs, ${ }^{5,6,27,45-47}$ and has been reported as an early step in human tumorigenesis and a contributing factor in the generation of aneuploid tumors. ${ }^{4,6,7,27,33,48-50}$ Tetraploidy also has its own tumorigenic potential, as only tetraploid, and not diploid, p53-null mouse mammary epithelial cells promote tumorigenesis after subcutaneous injection into nude mice. ${ }^{48}$

In addition to numerical chromosomal aberrations, GLI2 $\Delta \mathrm{N}$ overexpressing keratinocytes presented with structural chromosomal abnormalities, such as translocations. The 
identification of the clonal translocation $t(7 ; 14)$ both in near-tetraploid/aneuploid and diploid SINEG2 keratinocytes on GLI2 $\Delta \mathrm{N}$ induction suggests that this chromosome translocation event occurs in the diploid cell and thus the ability of GLI2 $\Delta \mathrm{N}$ to induce structural chromosomal aberrations is independent of the induction of tetraploidisation.

Here we propose two potential mechanisms by which $\mathrm{GLI} 2 \Delta \mathrm{N}$ is able to induce tetraploidisation. First, by indirectly downregulating $14-3-3 \sigma$, whose loss leads to the improper mitotic cap-independent translation of important executioners of mitosis, cytokinesis failure and accumulation of binucleate tetraploid cells, ${ }^{51}$ and is frequently seen in many cancers, including breast, prostate and BCCs. ${ }^{37,52}$ Second, the downregulation of $\mathrm{p} 21^{\mathrm{WAF} 1 / \mathrm{CIP} 1}$ upon $\mathrm{GLI} 2 \Delta \mathrm{N}$ induction in vitro, which was confirmed in human BCCs in vivo, might be another mechanism to promote tetraploidisation. As p21 $21^{\mathrm{WAF} 1 / \mathrm{CIP} 1}$ affects centrosome homeostasis, and its deficiency triggers a bona fide overduplication of centrioles and thus aberrant centrosome numbers, ${ }^{53}$ loss of $\mathrm{p} 21^{\mathrm{WAF} 1 / \mathrm{CIP} 1}$ may induce centrosome overduplication-associated cytokinesis failure, ${ }^{54}$ resulting in increased binucleated tetraploidy and genomic doubling.

Importantly, a low but detectable population of cells with $8 \mathrm{~N}$ DNA content was present in N/TERT and SINCE control cells. This suggests the presence of spontaneously arising tetraploid cells within the normal population. This is consistent with a report showing that human N/TERT keratinocytes have low rates of chromosomal non-disjunction during normal bipolar mitoses, which leads to the generation of binucleated tetraploid progenies ( $\sim 2 \%$ ) due to cytokinesis failure, instead of aneuploid progenies. ${ }^{6,46}$ However, the majority of N/TERT binucleated tetraploids did not proceed to the next division, ${ }^{46}$ possibly due to the activation of p53/p21 WAF1/CIP1-dependent checkpoint followed by apoptosis, previously shown to be responsible for the restricted growth potential of tetraploid cells. ${ }^{4,7,8,27,31-36}$ Consistently, a recent study ${ }^{55}$ showed that elevating chromosome missegregation rates alone in human cultured cells is not sufficient to convert stable, near-diploid cells into highly aneuploid cells with karyotypes resembling tumor cells. Thus, activation of oncogenes and/or loss of tumor suppressor genes might be necessary at a subsequent step, enabling binucleated tetraploid cells to survive, proliferate and potentially give rise to aneuploid cells. Taking into account the pivotal role of $\mathrm{p} 21^{\mathrm{WAF} 1 / \mathrm{CIP} 1}$ and $14-3-3 \sigma$ in the maintenance of genomic integrity of cells $s^{2,3,8,56}$ and the prevention of tetraploidisation and polyploidisation, ${ }^{4,7,51,53,57-59}$ the loss of both in GLI2 $\Delta \mathrm{N}$ expressing keratinocytes suggests a possible contribution not only in the production of binucleated tetraploid cells but also in the progression of cells with structural/numerical chromosomal abnormalities through G1/S and G2/M cell cycle phases, yielding polyploid and aneuploid progenies.

However, similar to the suppression of cell cycle regulators, the inhibition of tetraploidy-induced apoptosis by GLI2 overexpression may be critical in the generation of GIN. It is known that overexpressed BCL-2 inhibits apoptosis after a failed cell division, resulting in enhanced survival of tetraploid cells, which frequently undergo multipolar and asymmetric divisions, leading to aneuploidy and extensive chromosomal alterations. ${ }^{4,7,31,60}$ We found that $\mathrm{GLI} 2 \Delta \mathrm{N}$ induced $\mathrm{BCL}-2$ overexpression, and by pharmacological inhibition of $B C L-2$ we confirmed that in GLI2 $\Delta \mathrm{N}$-expressing keratinocytes, the anti-apoptotic function of BCL-2 is more important to those tetraploid/aneuploid cells than the genomically unchanged cells. This not only showed that loss of BCL-2 function can restore the apoptotic mechanism in GLI2 $\Delta \mathrm{N}$-expressing cells but also that genomically unstable cells rely much more on the apoptosis-prevention role of BCL-2 than genomically stable cells. In addition, by inhibiting the function of BCL-2 protein by Navitoclax we showed that increased basal levels of BCL-2 are responsible for the resistance of GLI2 $\Delta \mathrm{N}$ keratinocytes to UVB-mediated apoptosis. This is consistent with the apoptotic resistance, mediated by intrinsic or extrinsic pathways, in human BCCs. ${ }^{38,61,62}$ Overall, GLI2 $\Delta \mathrm{N}$-expressing keratinocytes are resistant to both chromosomal alteration-mediated and UVB/DNA-damage-induced apoptosis, and this may explain how cells with genomic aberrations are able to escape apoptosis and give rise to CIN.

The oncogenic activity of GLI2 interacts with a number of biological processes, leading to the inhibition of apoptosis, resistance to growth arrest and suppression of epithelial differentiation; as such, Gli2 $\Delta \mathrm{N}$ alone is sufficient for the generation of BCC tumors. ${ }^{17-19}$ In this study we show for the first time, to our knowledge, that activation of GLI2 $\Delta \mathrm{N}$ can induce GIN, a widespread feature of human cancer. There are two mechanisms that cause GIN: (a) the increased genomic alteration rate and (b) the loss of the surveillance of cells with genomic defects, leading to the accumulation of cells with genomic abnormalities. Our data suggest that GLI2 interferes with both processes to contribute to GIN. By suppressing the expression of both $\mathrm{p} 21^{\mathrm{WAF} 1 / \mathrm{CIP} 1}$ and $14-3-3 \sigma$, GLI2 stimulates CIN by increasing the rate of bi-/multinucleated cell generation. This, along with GLI2-stimulated BCL-2 overexpression, suppress checkpoint and apoptosis activation in response to endogenous (numerical and structural chromosomal alterations) and exogenous (UVB) DNA damage. Together, GLI2 promotes $\mathrm{CIN}$ and the accumulation of chromosomal abnormalities, which drive tumor formation. Although GIN is a hallmark of human cancer, we provide evidence, indicating that GLI2 may have a key role in driving such events in human neoplasms.

\section{Material and Methods}

Plasmids and cloning. The self-inactivating retroviral vector (pSIN)-MCS vector, containing an MCS insert, was cloned from pSIN-CMV-EGFP plasmid. ${ }^{63}$ The pSIN-CMV-GLI2 $\Delta N$-stable expression retroviral transduction vector was obtained by excising the CMV-EGFP-GLI2 $\Delta N$ ORF from pCMV-EGFP-GLI2 $\Delta N$ with Sall and Mfel and subcloning it into the pSIN-MCS vector cut with Xhol and EcoRI.

Cell lines and culture. Human telomerase reverse-transcriptase (h/TERT)immortalised N/TERT-1 are derived from clinically normal foreskin tissue and were supplied by Professor James Rheinwald (Department of Dermatology, Harvard University Medical School, Boston, MA, USA). The telomerase-immortalised cell line, N/TERT-1 (N/TERT) ${ }^{64}$ was chosen to examine GLI2 $\Delta \mathrm{N}$ effects because of its genotype, which is comparable to primary human keratinocytes. ${ }^{64}$ This line retains a functional p53/p21 $1^{\text {WAF1/CIP1 }}$ pathway, and although it has a potentially unlimited lifespan because of abrogated senescence, it is neither tumour derived nor malignant. ${ }^{64}$ N/TERT keratinocytes were cultured in Dulbecco's modified Eagle's medium (DMEM) high glucose, supplemented with 25\% (v/v) Ham's F12 medium (PAA, Somerset, UK), 10\% (v/v) fetal calf serum (FCS; Biosera, East Sussex, UK), 
$1 \%(\mathrm{v} / \mathrm{v})$ Glutamine (PAA), 1\% (v/v) penicillin/streptomycin (PAA) and various mitogens $(0.4 \mu \mathrm{g} / \mathrm{ml}$ hydrocortisone (Sigma-Aldrich, Dorset, UK), $0.1 \mathrm{nM}$ cholera toxin (BioMol, Exeter, UK), $5 \mu \mathrm{g} / \mathrm{ml}$ transferrin (Sigma-Aldrich), $20 \mathrm{pM}$ liothyronine (Sigma-Aldrich), $5 \mu \mathrm{g} / \mathrm{ml}$ insulin (Sigma-Aldrich) and $10 \mathrm{ng} / \mathrm{ml}$ epidermal growth factor (AbD Serotec, Kidlington, UK)). Pimary NHEKs were cultured in a low $\mathrm{CaCl}_{2}$ $(0.1 \mathrm{mM}$; Gibco, Paisley, UK) keratinocyte serum-free medium (K-SFM; Life Technologies, Paisley, UK), supplemented with $0.3 \mathrm{mM} \mathrm{CaCl} 2$ (Sigma-Aldrich), $25 \mu \mathrm{g} / \mathrm{ml}$ bovine pituitary extract (Life Technologies), $0.2 \mathrm{ng} / \mathrm{ml}$ human epidermal growth factor (Life Technologies) and 1\% (v/v) penicillin/streptomycin (PAA). Diploid SK-UT-1B cells were cultured in DMEM (PAA) high glucose, supplemented with $10 \%(\mathrm{v} / \mathrm{v}) \mathrm{FCS}, 1 \%(\mathrm{v} / \mathrm{v})$ penicillin/streptomycin and $1 \%(\mathrm{v} / \mathrm{v})$ glutamine. Phoenix (human embryonic epithelial 293T derived) cells supplied by Nolan Lab (Medical Center, Stanford University Medical School, Stanford, CA, USA), were cultured in DMEM supplemented with $10 \%$ (v/v) FCS, $1 \%$ (v/v) penicillin/ streptomycin and $1 \%(\mathrm{~V} / \mathrm{v})$ glutamine. All cells were grown at $37^{\circ} \mathrm{C}$ in a humidified atmosphere of either $5 \%$ (v/v) $\mathrm{CO}_{2} / 95 \%$ (v/v) air (for NHEK and SK-UT-1B) or $10 \%$ (v/v) $\mathrm{CO}_{2} / 90 \%$ (v/v) air (for N/TERT).

Retroviral infection. All transductions using pSIN-based constructs involved transfecting the plasmid into the Phoenix packaging cell line using Fugene 6 Transfection Reagent (Roche Diagnostics, Burgess Hill, UK), according to the manufacturer's instructions, followed by selection of the cells with $3 \mu \mathrm{g} / \mathrm{ml}$ puromycin (Sigma-Aldrich) for 7-10 days. Next, cells were incubated in normal growth medium at $32{ }^{\circ} \mathrm{C}$ overnight. The supernatant from virus-containing Phoenix cells was collected once daily, one to two times post confluence. To infect N/TERT keratinocytes, NHEK and SK-UT-1B cells were pre-incubated for $10 \mathrm{~min}$ at $37^{\circ} \mathrm{C}$ in normal growth medium containing $5 \mu \mathrm{g} / \mathrm{ml}$ polybrene (Sigma-Aldrich), before replacing with retroviral supernatant containing the same concentration of polybrene (Sigma-Aldrich). Cells were centrifuged $(350 \times g)$ at $32^{\circ} \mathrm{C}$ for $1 \mathrm{~h}$ before retroviral supernatant was replaced with normal growth medium and were kept in normal culture condition. Transduced cells were incubated for at least $24 \mathrm{~h}$ before being used for experiments. Because of lack of selectable markers, transduced cells were fluorescent-activated cell sorted and collected in order to enhance the percentage of cells that have the retroviral construct.

Fluorescent-activated cell sorting. All fluorescent activated cell sorting (FACS) runs (sorting based on enhanced green fluorescence protein - EGFP levels) were performed in a BD FACSAria Cell Sorter fitted with a Blue Argon Laser $488 \mathrm{~nm}$, violet diode $405 \mathrm{~nm}$ and red diode $633 \mathrm{~nm}$ (BD Biosciences, San Jose, CA, USA). After washing with $1 \times$ PBS, cell pellets were resuspended in $1 \times$ PBS each and then filtered through a $70-\mu \mathrm{m}$ strainer. N/TERT and NHEK and SK-UT-1B wild-type cells were used for obtaining basal levels of green fluorescence (background autofluorescence), and all cells above this basal threshold were considered as being EGFP-positive fluorescent cells, and were thus sorted and plated in normal growth medium.

Light and fluorescence microscopy. Normal cultured cells, cultured cells expressing EGFP or EGFP-GLI2 $\Delta$ N fusion protein were visualised using a light fluorescence microscope (Leica DM IRB/Nicon Eclipse TE-2000-S, Leica Microsystems, Milton Keynes, UK) to detect cell morphology and gene/protein expression. Images were captured with a digital imaging system (Leica DC2000 camera) attached to the microscope.

CAsy cell counter. Cell number and density of viable cells were determined using CAsy Cell Counter (Innovatis, Sittingbourne, UK). Each sample (cell suspension) was prepared three times in CAsyTon (Innovatis) buffer, followed by triplicate measurements of $200 \mu \mathrm{l}$ sample volume. Viable cells were measured by Casy Cell Counter, by excluding all counts that were of a size smaller that $10 \mu \mathrm{m}$ (dead cells and debris).

Proliferation assays. For MTT proliferation assay, cells were seeded in separate (one for each time point) 24-well plates. The next day, cells were incubated for $2 \mathrm{~h}$ in MTT (Sigma-Aldrich) and solution was prepared (growth medium containing $10 \%(\mathrm{v} / \mathrm{v})$ of MTT stock solution $5 \mathrm{mg} / \mathrm{ml}$ ) at $37^{\circ} \mathrm{C}$ in a humidified atmosphere of $10 \%(\mathrm{v} / \mathrm{v}) \mathrm{CO}_{2} / 90 \%$ (v/v) air (Day 0). MTT formazan crystals were solubilised in isopropanol (Fisher, Leicestershire, UK) and $100 \mu \mathrm{l}$ of the solution from each well was transferred to a well of a clear, flat-bottomed 96well plate (Nunc, Roskilde, Denmark). The absorbance (optical density) was measured at $560 \mathrm{~nm}$, using a 96-well microplate reader (FLUOSTAR OPTIMA microplate reader, BMG LABTECH, Aylesbury, UK). For Alamar Blue assay, cells were incubated in 10\% Alamar Blue (Invitrogen, Paisley, UK) solution in growth medium for $6 \mathrm{~h}$ at $37^{\circ} \mathrm{C}$ in a humidified atmosphere of $10 \%(\mathrm{v} / \mathrm{v}) \mathrm{CO}_{2} / 90 \%(\mathrm{v} / \mathrm{v})$ air (Day 0). Following incubation, $100 \mu \mathrm{l}$ of the target cell medium was obtained and added in each well of an opaque, flat-bottomed 96-well microtiter white plate (Nunc). Alamar Blue (Invitrogen) reduction (fluorescence) was read on a FLUOSTAR OPTIMA microplate reader (BMG LABTECH) at 544 excitation wavelength and at $590 \mathrm{~nm}$ emission wavelength. Next, medium containing the Alamar Blue (Invitrogen) was aspirated and cells were re-fed with fresh normal growth medium. Samples were analysed in six replicates.

Population doublings. Keratinocyte population doublings were calculated as follows: $\mathrm{PD}=3.32 \times\left(\log _{10}(\mathrm{~N} 1)-\log _{10}(\mathrm{~N} 0)\right)$, where $\mathrm{N} 1=$ total yield (total output) and $\mathrm{NO}=$ initial number of seeded keratinocytes. All PD values were individually collected (once every 4 days) and were used cumulatively.

Flow cytometry analysis. All flow cytometry analytical runs were performed on a BD LSRII fitted with a Blue Argon Laser $488 \mathrm{~nm}$, violet diode $405 \mathrm{~nm}$, red diode $633 \mathrm{~nm}$ and a UV laser $325 \mathrm{~nm}$ (BD Biosciences), using the BD FACSDiva Software (BD Biosciences).

For flow cytometry-Hoechst-33342 (Sigma-Aldrich) analysis, cells were trypsinised and centrifuged at 1000 r.p.m. for $5 \mathrm{~min}$. After washing with $1 \times$ PBS and spinning at 1000 r.p.m. for 5 min, cell pellets were resuspended in Hoechst-33342 $10 \mu \mathrm{g} / \mathrm{ml}$ in $1 \times$ PBS. After 1 -h incubation at $37^{\circ} \mathrm{C}$ in a humidified atmosphere of $10 \%(\mathrm{v} / \mathrm{v}) \mathrm{CO}_{2} / 90 \%(\mathrm{v} / \mathrm{v})$ air, cells were filtered through a $70-\mu \mathrm{m}$ strainer and cellular DNA content was measured by flow cytometry.

For flow cytometry-propidium iodide (Sigma-Aldrich) analysis, culture medium was centrifuged together with trypsinised cells to collect all cells, including detached cells, at 1500 r.p.m. for $5 \mathrm{~min}$. After washing with $1 \times$ PBS and spinning at 1500 r.p.m. for $5 \mathrm{~min}$, cell pellets were resuspended in ice-cold $70 \%$ (v/v) ethanol and incubated for $2 \mathrm{~h}$ at $4{ }^{\circ} \mathrm{C}$. Cells were then centrifuged at 6000 r.p.m. for $2 \mathrm{~min}$. Supernatant was aspirated and each pellet was washed in $1 \times$ PBS and centrifuged at 6000 r.p.m. for $2 \mathrm{~min}$. Cell pellets were then resuspended in $100 \mathrm{mM}$ $\mathrm{NaCitrate}$ (Sigma-Aldrich) each and centrifuged at 6000 r.p.m. for 2 min. Next, supernatant was aspirated and each pellet was resuspended in 300-500 $\mu \mathrm{l}$ PI/RNaseA mixture $(50 \mu \mathrm{g} / \mathrm{ml}$ propidium iodide, $125 \mu \mathrm{g} / \mathrm{ml}$ RNase A, $38 \mathrm{mM}$ NaCitrate, $1 \times$ PBS; all supplied by Sigma-Aldrich). Resuspended cells were incubated for 10-20 min in the dark at room temperature and cellular DNA content measurement by flow cytometry was carried out, where the same number of events was acquired for each sample (25000-50000 events). Samples were analysed either in duplicates or triplicates.

Cy5 Annexin V staining. For Cy5 Annexin V (BD Biosciences) and DAPI staining followed by flow cytometry analysis, equal numbers of N/TERT, SINCE and SINEG2 cells were seeded in 6-cm dishes, and collected either 24 or $48 \mathrm{~h}$ after plating, or were collected after $24 \mathrm{~h}$ of mock treatment or UVB treatment for $24 \mathrm{~h}$ in order to detect UVB-induced apoptosis. Culture media from each of UVBtreated culture dishes were also collected to include any detached dead or apoptotic cells that may be floating in the medium. After centrifugation, cells were resuspended in $100 \mu \mathrm{l}$ of $1 \times$ Annexin V-binding buffer solution (BD Biosciences) and $5 \mu \mathrm{l}$ Cy5 Annexin V antibody (BD Biosciences) or without antibody (negative controls). Resuspended cells were then gently vortexed and were incubated for $15 \mathrm{~min}$ at room temperature in the dark. Next, $400 \mu \mathrm{l}$ of $1 \times$ Annexin V-binding buffer solution (BD Biosciences) was added per sample and samples were kept on ice. Finally, DAPI (Sigma-Aldrich) was added at a final concentration of $200 \mathrm{ng} / \mathrm{ml}$ per sample, 1-2 min before the cells were given for flow cytometry analysis, where the same number of events was acquired for each sample (20000-30000 events). Samples were analysed in duplicates.

Nuclear staining. For Hoechst-33342 staining, cells were seeded at equal densities, and as soon as they reached $50-60 \%$ confluence they were washed, trypsinised and stained with $10 \mu \mathrm{g} / \mathrm{ml}$ Hoechst-33342 (Sigma-Aldrich) in suspension for $1 \mathrm{~h}$ at $37^{\circ} \mathrm{C}$. Cells were then seeded at equal densities, and digital bright-field and fluorescent images were captured 24,48 and $72 \mathrm{~h}$ ( $\sim 30-60 \%$ confluent throughout the experiment) after plating.

For DAPI staining, cells were fixed $72 \mathrm{~h}$ after plating ( $\sim 40-60 \%$ confluent) in $4 \%$ (v/v) formaldehyde/formalin (Fisher) solution for $20 \mathrm{~min}$ at room temperature and were stained with $200 \mathrm{ng} / \mathrm{ml}$ DAPI (Sigma-Aldrich) for $10 \mathrm{~min}$ at room temperature in 
the dark. Digital bright-field and fluorescent images ( $\sim 15$ images (fields) per cell line in two replicate wells) were captured using a fluorescence microscope. The binucleated (tetraploid) cells per field (image) were counted using Adobe Photoshop CS4 Extended (Adobe Systems Europe, Bergshire, UK). The percentage of binucleated cells per field was derived by counting the number of cells with two nuclei over the total number of cells per field. Thus, the percentage of binucleated cells per field $(x)$ was calculated as follows: $x=$ number of binucleate cells $\times 100 /$ total number of cells. An average of $\sim 300-350$ cells were counted for each cell line in total. Only binulceated cells were counted in this analysis, whereas all multinucleated cells were included in the total number of cells per field. Cells undergoing mitosis were also counted as two mononuclear cells.

Reverse-transcription PCR. Total RNA was extracted from cells using RNeasy Mini Kit (Qiagen, West Sussex, UK) and RNA (1-2 $\mu \mathrm{g})$ was reverse transcribed into cDNA with the Reverse transcription kit (Promega, Hampshire, UK) according to manufacturer's protocols.

Real-time quantitative PCR. Real-time quantitative PCR (qRT-PCR) was performed as previously described. ${ }^{65}$ Briefly, qRT-PCR runs were performed in the LightCycler 480 qPCR system (Roche Diagnostics). Relative quantification of mRNA transcripts was performed by LightCycler 480 Advanced Relative Quantification software (Roche Diagnostics) with at least two reference genes for each analytical run. Samples were analysed in triplicates and significance values were calculated by Graphpad Instat software (GraphPad Software, San Diego, CA, USA) by using two-sided $P$-values or using ANOVA analysis for multiple sample comparisons. All primer sequences are listed in the Supplementary Table S1. Using the GeNorm algorithm analysis method, ${ }^{66}$ and the LightCycler 480 Relative Quantification Software programme (Roche Diagnostics; with builtin multiple reference genes normalisation algorithm), of the eight reference genes (GAPDH, RPLPO, YAP1, UBC, HPRT1, POLR2A, ESD and 18S), two were identified as being most reliable and stable reference genes: polymerase (RNA) II (DNA directed) polypeptide A (POLR2A) and Yes-associated protein 1 (YAP1) across a large panel of normal and cancer human cells and tissues. ${ }^{65}$

Semiquantitative PCR. Semiquantitative PCR analysis was performed in Verity 96-well Thermal Cycler (Applied Biosystems, Foster City, CA, USA) for the visualisation of GLI2 (whole-gene amplification or $\alpha / \beta$-isoform-specific amplification) gene mRNA expression. Samples were run on a typical PCR amplification protocol $\left(95^{\circ} \mathrm{C}\right.$ for $10 \mathrm{~s}, 60^{\circ} \mathrm{C}$ for $6 \mathrm{~s}, 72{ }^{\circ} \mathrm{C}$ for $\left.6 \mathrm{~s}\right)$ for 36 cycles for GLI2 full-length and POLR2A, and to 27 and 30 cycles for GLI2 a/ $\beta$ and POLR2A, respectively. PCR products were visualised by UV light and a gel image was captured in the Autochemi imaging system (UVP). Primer sequences are listed in Supplementary Table S1.

Immunoblot analysis. Total cell protein extraction and immunoblot analysis was performed as previously described ${ }^{65}$ For the extraction of total protein from UVB-irradiated cells, culture media were also collected by centrifugation to include any dead or apoptotic cells in the medium. Primary antibodies used were: goat polyclonal anti-14-3-3 $\sigma$ (N-14, sc-7681, Santa Cruz, Heidelberg, Germany), mouse monoclonal anti-Bcl-2 (100, sc-509, Santa Cruz), rabbit polyclonal anti-Caspase-3 (Cell Signaling, Danvers, MA, USA), rabbit polyclonal anti-EGFP (ab-290, Abcam, Cambridge, UK), rabbit polyclonal anti-GLI2 (H300, Santa Cruz), mouse monoclonal anti-p21 WAF1/CIP1 (Santa Cruz), mouse monoclonal anti-p53 (DO1, CRUK, Lincoln's Inn Fields, London, UK) and mouse monoclonal anti- $\beta$-actin, Sigma-Aldrich). Secondary HRP antibodies were as follows: polyclonal rabbit antimouse immunoglobulin/HRP (DakoCytomation, Cambridgeshire, UK), polyclonal goat anti-rabbit immunoglobulin/HRP (DakoCytomation) and polyclonal rabbit antigoat immunoglobulin/HRP (DakoCytomation).

UVB irradiation. Initially, the growth medium of semiconfluent (50-65\%) cells was aspirated. The culture dishes were then inserted in the UV cross-linker (UVP) and the lids were removed. Cells were irradiated with UVB at different doses $\left(10-30 \mathrm{~mJ} / \mathrm{cm}^{2}\right)$ and fresh growth medium was replaced immediately after UVB exposure. Routine calibration was performed to ensure UVB emission peak at $312 \mathrm{~nm}$, which is physiologically relevant to skin photobiology. Similar procedure was followed for the control cells except the UVB-exposure step (non-UVB-treated control cells).

Navitoclax (ABT-263) treatment. Cells were grown in monolayer until $\sim 60 \%$ confluence. Next, cells were treated with a range of different doses of
Navitoclax (ABT-263) dissolved in DMSO. Untreated cells were always used as controls and exposed to equal volume of DMSO as for treated cells. Navitoclax (ABT-263) was purchased from Selleck Chemicals (Houston, TX, USA).

Multiplex fluorescent in situ hybridisation. Metaphase cells were collected by standard cytogenetic methods. Twenty four-colour FISH was carried out as previously described ${ }^{67,68}$ by following the Vysis M-FISH protocol and using the SpectraVysion DNA probe (Abbott Molecular, Berkshire, UK). The computer software SpectroVision (Abbott Molecular) was used to capture and analyse the images. More than $10 \mathrm{M}$-FISH karyotypes were analysed for each cell line and rearrangements detected in two or more metaphases were considered as clonal.

Immunohistochemistry analysis of BCC clinical samples. The protein expression levels of p21 ${ }^{\text {WAF1/CIP1 }}$ (p21) were examined in 16 biopsies comprising normal skin and human BCC subtypes, including nodular $(n=9)$, superficial $(n=4)$ and infiltrative $(n=3)$. Immunohistochemistry analysis of p21 $1^{\text {WAF } 1 / C I P 1}$ was performed using $221^{\text {WAF1/CIP1 }}$ mouse monoclonal antibody (DCS60, Cell Signaling) at 1:125 dilution. Tissue processing and tissue sections were cut at the Pathology Department of the Institute of Cancer, Barts and the London School of Medicine and Dentistry, Charterhouse Square, London, UK. Briefly, $4-\mu \mathrm{m}$ tissue sections were cut from the BCC paraffin blocks and transferred on to charged microscope slides. The slides were dried in a $37-{ }^{\circ} \mathrm{C}$ oven overnight and then run on Ventana discovery platform (Ventana Molecular Discovery Systems, Roche Diagnostics) with an automated protocol, including deparaffinisation, primary and secondary antibody incubation, DAB application, haematoxylin and bluing reagent counterstaining and finally slides cleaning. After the run was completed, the slides were placed in soapy tap water and rinsed under the tap for $1 \mathrm{~min}$ and then placed in $\mathrm{dH}_{2} \mathrm{O}$. Following dehydration in a series of solvents, the slides were mounted with coverslips.

Affymetrix $10 \mathrm{~K}$ SNP analysis. Genomic DNA samples were purified and processed as described previously. ${ }^{65}$ Briefly, $350-500 \mathrm{ng}$ of DNA was digested with $X$ bal and ligated to the Xbal adaptor before PCR amplification using AmpliTaq Gold with Buffer II (Applied Biosystems). The PCR amplification profile on an MJ DNA Engine thermal cycler was: 95/180 (hot start) and 95/20, 59/15, $72 / 60\left({ }^{\circ} \mathrm{C} / \mathrm{s}\right)$ for 40 cycles followed by a termination step at $72{ }^{\circ} \mathrm{C}$ for $7 \mathrm{~min}$. PCR products were purified using Ultrafree-MC 30000 NMWL filter columns (catalogue number UFC-3LTKO0; Millipore, Watford, UK) and DNA concentrations determined using NanoDrop spectrophotometer. Hybridisation and scanning of the arrays were processed as described previously. ${ }^{65}$ Evaluation of genomic copy number alterations was performed using Affymetrix Copy Number Analysis Tool software (CNAT, version 4) where the threshold for statistical significance was $P \leq 10^{-6}$ as recommended by Affymetrix. The data was cross verified and genome ploidy \pm S.D. for Log2 ratio values were obtained using an independent algorithm, Copy Number Analyzer for GeneChip (version 2; Department of Regeneration Medicine, University of Tokyo, Tokyo, Japan). Average SNP call rates for all chips were $95-99 \%$.

Statistical analysis. Statistical analysis was performed using either the Microsoft Excel's software or the GraphPad's InStat (V2-04a) and Prism Software (V5,0; GraphPad Software) for Student's t-test analysis.

\section{Conflict of Interest}

The authors declare no conflict of interest.

Acknowledgements. We thank Professor James Rheinwald (Harvard University Medical School) for providing the N/TERT-1 (N/TERT) cell line and the culture conditions for NHEK. We are grateful to Professor Paul Khavari (Stanford University School of Medicine) for providing the retroviral pSIN-CMV-EGFP plasmid and Professor Fritz Aberger (University of Salzburg) for providing the pCMV-EGFPGLI2 $\Delta N$ plasmid. We also thank Professor Kenneth E Parkinson for his constructive comments. This work was supported by grant DERG1D8R from the Research Advisory Board of the Barts and the London Charity.

1. Hanahan D, Weinberg RA. The hallmarks of cancer. Cell 2000; 100: 57-70.

2. Jefford CE, Irminger-Finger I. Mechanisms of chromosome instability in cancers. Crit Rev Oncol Hematol 2006; 59: 1-14. 
3. Lobrich $M$, Jeggo PA. The impact of a negligent G2/M checkpoint on genomic instability and cancer induction. Nat Rev 2007; 7: 861-869.

4. Zhivotovsky B, Kroemer G. Apoptosis and genomic instability. Nat Rev Mol Cell Biol 2004; 5: 752-762.

5. Rajagopalan H, Lengauer C. Aneuploidy and cancer. Nature 2004; 432: 338-341.

6. Ganem NJ, Storchova Z, Pellman D. Tetraploidy, aneuploidy and cancer. Curr Opin Genet Dev 2007; 17: 157-162.

7. Vitale I, Galluzzi L, Senovilla L, Criollo A, Jemaa M, Castedo M et al. Illicit survival of cancer cells during polyploidization and depolyploidization. Cell Death Differ 2011; 18: 1403-1413.

8. Lane DP. Cancer. p53, guardian of the genome. Nature 1992; 358: 15-16.

9. Ribeiro GR, Francisco G, Teixeira LV, Romao-Correia RF, Sanches JA Jr, Neto CF et al. Repetitive DNA alterations in human skin cancers. J Dermatol Sci 2004; 36: 79-86.

10. Jayaraman SS, Rayhan DJ, Hazany S, Kolodney MS. Mutational landscape of basal cell carcinomas by whole exome sequencing. J Invest Dermatol 2014; 134: 213-220.

11. Teh MT, Blaydon D, Chaplin T, Foot NJ, Skoulakis S, Raghavan M et al. Genomewide single nucleotide polymorphism microarray mapping in basal cell carcinomas unveils uniparental disomy as a key somatic event. Cancer Res 2005; 65 : 8597-8603.

12. Janisson-Dargaud D, Durlach $A$, Lorenzato $M$, Grange $F$, Bernard $P$, Birembaut $P$. Aneuploidy, but not Ki-67 or EGFR expression, is associated with recurrences in basal cell carcinoma. J Cutan Pathol 2008; 35: 916-921.

13. Jin Y, Martins C, Salemark L, Persson B, Jin C, Miranda J et al. Nonrandom karyotypic features in basal cell carcinomas of the skin. Cancer Genet Cytogenet 2001; 131: 109-119.

14. Pavarino EC, Antonio JR, Pozzeti EM, Larranaga HJ, Tajara EH. Cytogenetic study of neoplastic and nonneoplastic cells of the skin. Cancer Genet Cytogenet 1995; 85: 16-19.

15. Ashton KJ, Carless MA, Griffiths LR. Cytogenetic alterations in nonmelanoma skin cancer: a review. Genes Chromosomes Cancer 2005; 43: 239-248.

16. Epstein EH. Basal cell carcinomas: attack of the hedgehog. Nat Rev 2008; 8: 743-754.

17. Grachtchouk M, Mo R, Yu S, Zhang X, Sasaki H, Hui CC et al. Basal cell carcinomas in mice overexpressing Gli2 in skin. Nat Genet 2000; 24: 216-217.

18. Grachtchouk M, Pero J, Yang SH, Ermilov AN, Michael LE, Wang A et al. Basal cell carcinomas in mice arise from hair follicle stem cells and multiple epithelial progenitor populations. J Clin Invest 2011; 121: 1768-1781.

19. Hutchin ME, Kariapper MS, Grachtchouk M, Wang A, Wei L, Cummings D et al. Sustained Hedgehog signaling is required for basal cell carcinoma proliferation and survival: conditional skin tumorigenesis recapitulates the hair growth cycle. Genes Dev 2005; 19: 214-223.

20. Ji J, Kump E, Wernli M, Erb P. Gene silencing of transcription factor Gli2 inhibits basal cell carcinomalike tumor growth in vivo. Int J Cancer 2008; 122: 50-56.

21. Beachy PA, Karhadkar SS, Berman DM. Tissue repair and stem cell renewal in carcinogenesis. Nature 2004; 432: 324-331.

22. Zhang D, Cao L, Li Y, Lu H, Yang X, Xue P. Expression of glioma-associated oncogene 2 (Gli 2) is correlated with poor prognosis in patients with hepatocellular carcinoma undergoing hepatectomy. World J Surg Oncol 2013; 11: 25.

23. Mazumdar T, DeVecchio J, Shi T, Jones J, Agyeman A, Houghton JA. Hedgehog signaling drives cellular survival in human colon carcinoma cells. Cancer Res 2011; 71 : 1092-1102.

24. Alexaki VI, Javelaud D, Van Kempen LC, Mohammad KS, Dennler S, Luciani F et al. GLI2-mediated melanoma invasion and metastasis. J Natl Cancer Inst 2010; 102: 1148-1159.

25. Ruiz i Altaba A, Sanchez P, Dahmane N. Gli and hedgehog in cancer: tumours, embryos and stem cells. Nat Rev 2002; 2: 361-372.

26. Sterling JA, Oyajobi BO, Grubbs B, Padalecki SS, Munoz SA, Gupta A et al. The hedgehog signaling molecule Gli2 induces parathyroid hormone-related peptide expression and osteolysis in metastatic human breast cancer cells. Cancer Res 2006; 66: 7548-7553.

27. Storchova Z, Kuffer C. The consequences of tetraploidy and aneuploidy. J Cell Sci 2008; 121(Pt 23): 3859-3866.

28. Thiyagarajan S, Bhatia N, Reagan-Shaw S, Cozma D, Thomas-Tikhonenko A, Ahmad N et al. Role of GLI2 transcription factor in growth and tumorigenicity of prostate cells. Cancer Res 2007; 67: 10642-10646.

29. Snijders AM, Huey B, Connelly ST, Roy R, Jordan RC, Schmidt BL et al. Stromal control of oncogenic traits expressed in response to the overexpression of GLI2, a pleiotropic oncogene. Oncogene 2008; 28: 625-637.

30. Hirotsu M, Setoguchi T, Sasaki H, Matsunoshita Y, Gao H, Nagao H et al. Smoothened as a new therapeutic target for human osteosarcoma. Mol Cancer 2010; 9: 5.

31. Castedo M, Coquelle A, Vivet S, Vitale I, Kauffmann A, Dessen P et al. Apoptosis regulation in tetraploid cancer cells. EMBO J 2006; 25: 2584-2595.

32. Lanni JS, Jacks T. Characterization of the p53-dependent postmitotic checkpoint following spindle disruption. Mol Cell Biol 1998; 18: 1055-1064.

33. Storchova Z, Pellman D. From polyploidy to aneuploidy, genome instability and cancer. Nat Rev Mol Cell Biol 2004; 5: 45-54.
34. Borel F, Lohez OD, Lacroix FB, Margolis RL. Multiple centrosomes arise from tetraploidy checkpoint failure and mitotic centrosome clusters in p53 and RB pocket proteincompromised cells. Proc Natl Acad Sci USA 2002; 99: 9819-9824.

35. Margolis RL, Lohez OD, Andreassen PR. G1 tetraploidy checkpoint and the suppression of tumorigenesis. J Cell Biochem 2003; 88: 673-683.

36. Andreassen PR, Lohez OD, Lacroix FB, Margolis RL. Tetraploid state induces p53-dependent arrest of nontransformed mammalian cells in G1. Mol Biol Cell 2001; 12: 1315-1328.

37. Lodygin D, Yazdi AS, Sander CA, Herzinger T, Hermeking H. Analysis of 14-3-3sigma expression in hyperproliferative skin diseases reveals selective loss associated with CpG-methylation in basal cell carcinoma. Oncogene 2003; 22: 5519-5524.

38. Regl G, Kasper M, Schnidar H, Eichberger T, Neill GW, Philpott MP et al. Activation of the BCL2 promoter in response to Hedgehog/GLI signal transduction is predominantly mediated by GLI2. Cancer Res 2004; 64: 7724-7731.

39. Tse C, Shoemaker AR, Adickes J, Anderson MG, Chen J, Jin S et al. ABT-263: a potent and orally bioavailable Bcl-2 family inhibitor. Cancer Res 2008; 68: 3421-3428.

40. Vogler M, Dinsdale D, Dyer MJ, Cohen GM. Bcl-2 inhibitors: small molecules with a big impact on cancer therapy. Cell Death Differ 2009; 16: 360-367.

41. Ikram MS, Neill GW, Regl G, Eichberger T, Frischauf AM, Aberger F et al. GLI2 is expressed in normal human epidermis and BCC and induces GLI1 expression by binding to its promoter. J Invest Dermatol 2004; 122: 1503-1509.

42. Regl G, Neill GW, Eichberger T, Kasper M, Ikram MS, Koller J et al. Human GLI2 and GLI1 are part of a positive feedback mechanism in Basal Cell Carcinoma. Oncogene 2002; 21: 5529-5539.

43. Tojo M, Kiyosawa H, Iwatsuki K, Nakamura K, Kaneko F. Expression of the GLI2 oncogene and its isoforms in human basal cell carcinoma. Br J Dermatol 2003; 148 : 892-897.

44. O'Driscoll L, McMorrow J, Doolan P, McKiernan E, Mehta JP, Ryan E et al. Investigation of the molecular profile of basal cell carcinoma using whole genome microarrays. Mol Cancer 2006; 5 : 74.

45. Olaharski AJ, Sotelo R, Solorza-Luna G, Gonsebatt ME, Guzman P, Mohar A et al. Tetraploidy and chromosomal instability are early events during cervical carcinogenesis. Carcinogenesis 2006; 27: 337-343.

46. Shi Q, King RW. Chromosome nondisjunction yields tetraploid rather than aneuploid cells in human cell lines. Nature 2005; 437: 1038-1042.

47. Miller SJ. Biology of basal cell carcinoma (Part I). J Am Acad Dermatol 1991; 24: 1-13.

48. Fujiwara T, Bandi M, Nitta M, Ivanova EV, Bronson RT, Pellman D. Cytokinesis failure generating tetraploids promotes tumorigenesis in p53-null cells. Nature 2005; 437 : 1043-1047.

49. Galipeau PC, Cowan DS, Sanchez CA, Barrett MT, Emond MJ, Levine DS et al. 17p (p53) allelic losses, 4N (G2/tetraploid) populations, and progression to aneuploidy in Barrett's esophagus. Proc Natl Acad Sci USA 1996; 93: 7081-7084.

50. Duelli D, Lazebnik Y. Cell-to-cell fusion as a link between viruses and cancer. Nat Rev 2007; 7: 968-976.

51. Wilker EW, van Vugt MA, Artim SA, Huang PH, Petersen CP, Reinhardt $\mathrm{HC}$ et al. 14-33sigma controls mitotic translation to facilitate cytokinesis. Nature 2007; 446: 329-332.

52. Lodygin $D$, Hermeking $H$. The role of epigenetic inactivation of 14-3-3sigma in human cancer. Cell Res 2005; 15: 237-246.

53. Duensing A, Ghanem L, Steinman RA, Liu Y, Duensing S. p21(Waf1/Cip1) deficiency stimulates centriole overduplication. Cell Cycle (Georgetown, TX) 2006; 5: 2899-2902.

54. Fukasawa K. Oncogenes and tumour suppressors take on centrosomes. Nat Rev 2007; 7 911-924.

55. Thompson SL, Compton DA. Examining the link between chromosomal instability and aneuploidy in human cells. J Cell Biol 2008; 180: 665-672.

56. Hermeking H, Lengauer C, Polyak K, He TC, Zhang L, Thiagalingam S et al. 14-3-3 sigma is a p53-regulated inhibitor of G2/M progression. Mol Cell 1997; 1: 3-11.

57. Dhar S, Squire JA, Hande MP, Wellinger RJ, Pandita TK. Inactivation of 14-3-3sigma influences telomere behavior and ionizing radiation-induced chromosomal instability. Mol Cell Biol 2000; 20: 7764-7772.

58. Mantel C, Braun SE, Reid S, Henegariu O, Liu L, Hangoc G et al. p21(cip-1/waf-1) deficiency causes deformed nuclear architecture, centriole overduplication, polyploidy, and relaxed microtubule damage checkpoints in human hematopoietic cells. Blood 1999; 93: $1390-1398$.

59. Stewart ZA, Leach SD, Pietenpol JA. p21(Waf1/Cip1) inhibition of cyclin E/Cdk2 activity prevents endoreduplication after mitotic spindle disruption. Mol Cell Biol 1999; 19: 205-215.

60. Nelson DA, Tan TT, Rabson AB, Anderson D, Degenhardt K, White E. Hypoxia and defective apoptosis drive genomic instability and tumorigenesis. Genes Dev 2004; 18 : 2095-2107.

61. Erb P, Ji J, Wernli M, Kump E, Glaser A, Buchner SA. Role of apoptosis in basal cell and squamous cell carcinoma formation. Immunol Lett 2005; 100: 68-72.

62. Kump E, Ji J, Wernli M, Hausermann P, Erb P. Gli2 upregulates cFlip and renders basal cell carcinoma cells resistant to death ligand-mediated apoptosis. Oncogene 2008; 27: 3856-3864.

63. Deng H, Lin Q, Khavari PA. Sustainable cutaneous gene delivery. Nat Biotechnol 1997; 15: 1388-1391. 
64. Dickson MA, Hahn WC, Ino Y, Ronfard V, Wu JY, Weinberg RA et al. Human keratinocytes that express hTERT and also bypass a p16(INK4a)-enforced mechanism that limits life span become immortal yet retain normal growth and differentiation characteristics. Mol Cell Biol 2000; 20: 1436-1447.

65. Gemenetzidis E, Bose A, Riaz AM, Chaplin T, Young BD, Ali M et al. FOXM1 upregulation is an early event in human squamous cell carcinoma and it is enhanced by nicotine during malignant transformation. PLoS One 2009; 4: e4849.

66. Vandesompele J, De Preter K, Pattyn F, Poppe B, Van Roy N, De Paepe A et al Accurate normalization of real-time quantitative RT-PCR data by geometric averaging of multiple internal control genes. Genome biology 2002; 3: research0034.1-research0034.11.

67. Mao X, Young BD, Chaplin T, Shipley J, Lu YJ. Subtle genomic alterations and genomic instability revealed in diploid cancer cell lines. Cancer Lett 2008; 267: 49-54.
68. Strefford JC, Lillington DM, Young BD, Oliver RT. The use of multicolor fluorescence technologies in the characterization of prostate carcinoma cell lines: a comparison of multiplex fluorescence in situ hybridization and spectral karyotyping data. Cancer Genet Cytogenet 2001; 124: 112-121.

(c) (i) Cell Death and Disease is an open-access journal published by Nature Publishing Group. This work is licensed under a Creative Commons Attribution 3.0 Unported License. To view a copy of this license, visit http://creativecommons.org/ licenses/by/3.0/

Supplementary Information accompanies this paper on Cell Death and Disease website (http://www.nature.com/cddis) 